\title{
The diagnostic utility of microCT for assessing bioerosion in archaeological bone
}

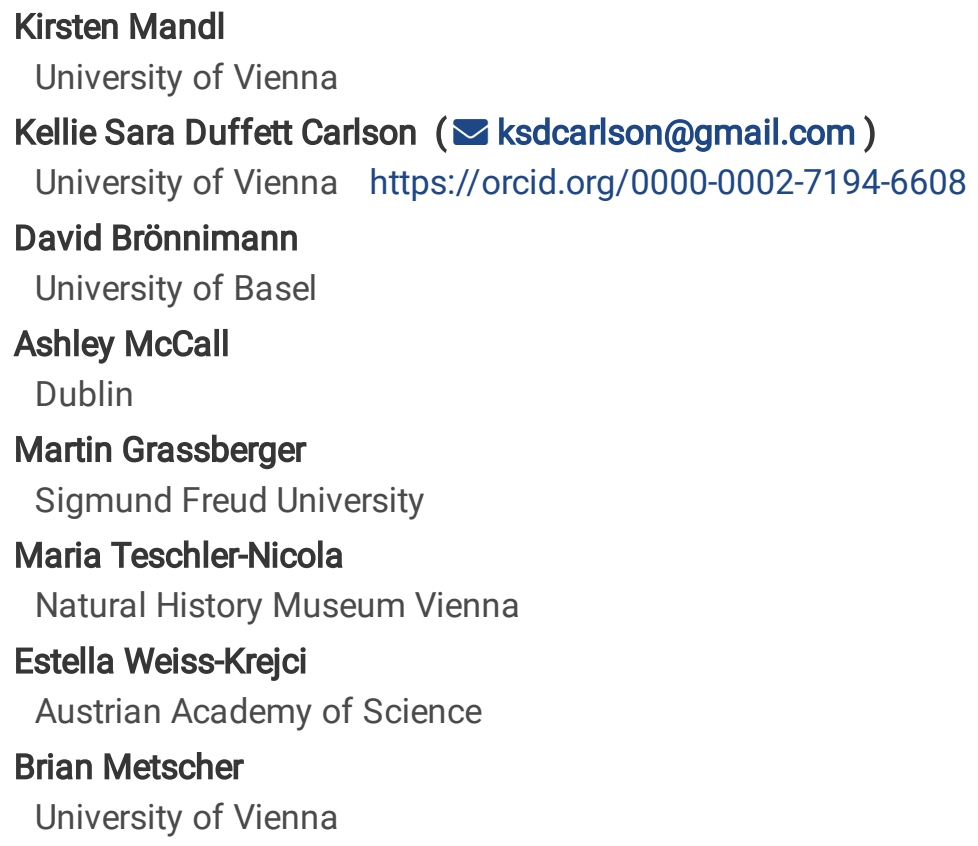

\section{Research Article}

Keywords: bone histology, microCT, mortuary archaeology, bioanthropology, bioerosion, histotaphonomy

Posted Date: October 25th, 2021

DOI: https://doi.org/10.21203/rs.3.rs-995605/v1

License: (c) (i) This work is licensed under a Creative Commons Attribution 4.0 International License. Read Full License 


\section{Abstract}

Recent advances have broadened the application of palaeoradiology for non-destructive investigation of ancient remains. X-ray microtomography (microCT) in particular is increasingly used as an alternative to histological bone sections for interpreting pathological alterations, trauma, microstructure, and more recently bioerosion with direct or ancillary use of histological indices. However, no systematic attempt has been made to confirm the reliability of microCT for histotaphonomic analysis of archaeological bone. The objectives of this study are therefore to (1) compare thin sections of human femora rated with the Oxford Histological Index to microCT sections using a newly developed Virtual Histological Index, and (2) provide an accessible methodology for the evaluation and visualization of bioerosion in archaeological bone using virtual anthropology techniques. We provide detailed descriptions of virtual sections and volume renderings, and also assess the efficacy of the method on cranial and postcranial elements, cremated long bones, and faunal samples. Furthermore, the need for time-consuming image segmentation is reduced by applying two noise-reducing, edge-preserving filters, and rendering with a colormap chosen to visualize bioerosion along with canal structure and density in 3D. The histological and virtual methods showed a strong correlation, providing the first systematic data substantiating lab-based microCT as a suitable alternative tool for reconstructing post-mortem history in the archaeological record, and for the reliable, non-destructive screening of samples for further analyses.

\section{Introduction}

As human remains offer unique perspectives on burial behavior in the past, the continued development and testing of bioarchaeological methods and techniques play an important role in refining our understanding of long term taphonomic processes. In recent years there have been numerous histotaphonomic studies of archaeological human and faunal bone that have looked at bioerosion to understand the mechanisms by which a corpse turns into a skeleton (e.g., Booth, 2016, 2017; Brönnimann et al., 2018; Fernández-Jalvo et al., 2010; Hollund et al., 2012, 2018; Smith et al., 2002; Turner-Walker \& Peacock, 2008). Although there is disagreement concerning the origin of bioeroding microorganisms and what histotaphonomic analysis can truly tell us about early taphonomic events (Kontopoulos et al., 2016; Turner-Walker, 2019), such analyses have proven to be highly effective for assessing the presence and type of bioerosion in archaeological bone. To improve the accessibility of histotaphonomic research in archaeology, this paper tests the utility of lab-based microCT and presents the Virtual Histological Index (VHI) as a rapid and minimally destructive method for the reconstruction of the early post-mortem history of archaeological bone.

Human bone is a composite material consisting in its molecular structure of a mineral phase, namely hydroxyapatite $\left(\mathrm{Ca}_{10}\left(\mathrm{PO}_{4}\right)_{6}(\mathrm{OH})_{2}\right)$, and an organic phase ( 90 \% collagen Type I, 5 \% non-collagenous proteins, 2 \% lipids) (Boskey, 2013), which presents macroscopically in two morphological forms: the compact cortical layer, and the loosely organized spongy matrix of cancellous (trabecular) bone. It can further be described histologically as mature (lamellar) and immature (woven), the latter of which is temporary, being replaced by mature bone during growth and by remodeling (White et al., 2012). Cortical bone, the focus of this paper, is the dense, hard shell that surrounds the medullary cavity of long bones and is bounded externally by the periosteum and internally by the endosteum. It is comprised of dense accumulations of lamellar type bone, which is-in cross-section under magnification with polarized light-visualized as bundles of concentric lamellae between parallel collagen fibers, each surrounding a longitudinal Haversian canal ( 97 $\mu \mathrm{m}$ in diameter for femora: Frost, 1961) that contains blood and lymphatic vessels, and nerve fibers that are linked with transverse Volkmann canals (Safadi et al., 2009). Each of these units forms a secondary osteon or Haversian system $(\sim 256 \mu \mathrm{m}$ in diameter for femora: Frost, 1961) that travels the long axis of the bone. Running through the lamellae in a radial pattern are small channels (canaliculi) that contain osteocyte processes (Safadi et al., 2009). In adult bone concentric rings of highly mineralized layers (cement lines) encircle the Haversian system from the surrounding matrix (White et al., 2012). Several antemortem factors affect living bone tissue, including the age, sex, diet, and health of the individual, which may be evident in the histological anatomy.

Taphonomy describes the post-mortem history of bone from the point of death onwards, while the post-burial history specifically is referred to as diagenesis, a process that is primarily microscopic (Millard, 2001; Turner-Walker, 2012). The 
restructuring or destruction of bone microanatomy by microorganisms, such as fungi and bacteria, is referred to as biogenic bone degradation, or bioerosion (Piepenbrink, 1986; Turner-Walker, 2012). Upon death, at the outset of the post-mortem interval, bone is beset by osteolytic micro-organismal activity induced by the host's enteric microbiome and/or by microbiota in the burial environment, which affect its surface and microstructure, eroding the histological anatomy (Brönnimann et al., 2018; Child, 1995; Damann \& Jans, 2017; Janaway, 1996; Jans, 2008; Kontopoulos et al., 2016; Metcalf et al., 2016; White \& Booth, 2014). This not only influences chemical and radiological analyses but is also-along with other factors such as the $\mathrm{pH}$ value of the soil- responsible for the fragile nature of archaeological skeletons (Millard, 2001; Nielsen-Marsh et al., 2007). Environments that favor the proliferation of osteolytic bacteria or saprophagous organisms, such as fungi, lead to increased destruction of the microanatomy. Depending on soil conditions, bioerosive processes can occur rapidly (Marchiafava et al., 1974; Wedl, 1865; but see Kendall et al., 2018), potentially within the first few months of deposition (Bell et al., 1996).

Bioerosion can be separated into three broad categories (Hackett, 1981; Jackes et al., 2001; Marchiafava et al., 1974; TurnerWalker, 2012; Wedl, 1865) defined according to their origins, infill, and size (1) fungi-induced Wedl tunnelling, also called centrifugal tunnelling (5 $\mu \mathrm{m}$ in diameter, typical dendritic shape), (2) cyanobacteria-induced tunnelling (10-15 $\mu \mathrm{m}$, less dendritic, limited to the outer 1-2 mm of bone surfaces), which primarily occurs in aquatic environments, and (3) osteolytic bacteria-induced non-Wedl tunneling (Brönnimann et al., 2018; Jans, 2008; Turner-Walker, 2019). Osteolytic bacteria cause microscopic focal destructions (MFDs) that result from solubilization, leaching, or redistribution of hydroxyapatite (HAp); these reorganize, but do not erase the bone matrix (Balzer et al., 1997; Child, 1995; Hackett, 1981; Jans, 2008; Jans et al., 2004) (Fig. 1a \& c). Hackett (1981) further described three categories of non-Wedl tunnelling that can be histologically differentiated by size, shape, lamellate content, and the presence or lack of a hypermineralized cuff: (a) linear longitudinal (5-10 $\mu \mathrm{m}$ in diameter); (b) budded (30-60 $\mu \mathrm{m}$ in diameter), and (c) lamellate (10-60 $\mu \mathrm{m}$ in diameter) (Jans, 2008; Jans et al., 2004). Specific organisms cannot easily be identified as causative agents based on the size or morphology of MFDs (Jans et al., 2004; Kendall et al., 2018; Turner-Walker, 2012). Osteolytic bacteria are the primary cause of bioerosion in archaeological human bone (Balzer et al., 1997; Jackes et al., 2001; Jans et al., 2004; Yoshino et al., 1991), with linear longitudinal and budded MFDs most frequently encountered, representing $85 \%$ of bacterial attack; lamellate tunnelling, which is less common, is infrequently found alone (Jans et al., 2004), and is observed surrounding the rim of the Haversian systems. Fungal tunnelling is less frequently observed in human than animal bone, as MFD in the former often destroys the bone microstructure, obscuring other traces of bioerosion (Jans et al., 2004).

Fig. 1 Light micrographs showing the described histological features. (a) Inhibited bioerosion (MFD) and recrystallization in canals in femoral sample S01. The blue and yellow visualize collagen birefringence. The micrograph was taken with a lambda plate and 10(2x) magnification. (b) Very good collagen preservation and inhibited bioerosion in femoral sample GÖ01. The micrograph was taken with polarized light and $4(1 \times)$ magnification. (c) Inhibited bioerosion around Haversian canals $(H)$ with Wedl type-2 tunnelling (W2) identified by enlarged canaliculi in femoral sample Gö01. The micrograph was taken with polarized light and $10(2 \times)$ magnification

To date most research on microscopic taphonomic alteration to bone has been performed using histology via light microscopy or scanning electron microscopy (SEM) (e.g., Hackett, 1981; Garland, 1987; Grupe \& Garland, 1993; Turner-Walker, 2012; TurnerWalker \& Jans, 2008). However, recent technical developments enable high-resolution non-destructive 3D imaging of archaeological samples. X-ray microtomography (microCT, or XRM) is a non-destructive imaging procedure that computes a stack of cross sections through an object from a series of 2D radiographic projections. This 3D volume dataset is composed of volumetric pixels (voxels), each of which has a specific grey-scale value representing local X-ray attenuation as well as accurate size calibration (Withers et al., 2021). The microfocus X-ray tubes used in lab-based microCT scanners provide excellent image resolution, down to a few $\mu \mathrm{m}$ or less, which permit the accurate description of the minute physical properties of both the internal and external skeleton (Moore, 2013; Scherf, 2013) without, in most cases, causing tissue damage (e.g., DNA degradation: Walton et al., 2015)

Volume image data obtained from tomographic methods allow the rendering and analysis of 3D models using dedicated software. Studies in the fields of palaeontology (Higgs et al., 2011), and anthropology (Le Garff et al., 2017) applied X-ray microtomography (microCT) to bone to identify different types of diagenesis, and in combination with histological indices 
(Booth et al., 2016; Dal Sasso et al., 2014), while others have used SEM (Turner-Walker \& Syversen, 2002) or synchrotron radiation microCT (SR-microCT) (Caruso et al., 2020). Dal Sasso et al. (2014) and Booth et al. (2016) were amongst the first to see the value of microCT scanning for the evaluation of diagenetic alteration to archaeological bone. Caruso et al. (2020) used SR-microCT in combination with minero-chemical methods to identify diagenesis in modern and archaeological remains, which included the creation of volume renderings to visualize vascular and canal networks with an unspecified filter without systematically assessing the presence of MFD, nor in comparison to the histological index they used on thin sections with optical microscopy. Both Dal Sasso et al. (2014) and Booth et al. (2016) assessed virtual tomographic thin sections and created grey-scale volume renderings to visualize diagenesis. Though innovative at the time, these volume renderings can be improved upon by the application of noise-reducing, edge-preserving filters, and the use of a colormap with artificial shading that provides increased contrast range to better differentiate between unaltered bone and demineralized, bioeroded bone. Moreover, though both Dal Sasso et al. (2014) and Booth et al. (2016) state that virtual cross-sections are comparable to thin section micrographs as rated via the Oxford Histological Index $(\mathrm{OHI})$, there has been no systematic attempt to confirm this, nor the broader utility of this technology for visualizing or investigating microscopic diagenetic alterations in comparison to the well-established method of histotaphonomy.

Importantly, studies comparing microCT images with histology to evaluate skeletal trauma (Baier et al., 2019), pathological alterations (Rühli et al., 2007), bone morphometry (Müller et al., 1998; Uchiyama et al., 1997), and cortical bone microstructure (Particelli et al., 2012), identify strong correlations between conventional histological section methods and virtual assessments. Therefore, comparing bioerosion in thin sections with virtual sections is a crucial first step towards confirming the reliability of microCT for identifying microscopic taphonomic alterations to bone. The dual aims of this research are thus to (1) systematically compare transverse thin sections rated with the $\mathrm{OHI}$ to microCT scan images using a newly developed $\mathrm{VHI}$, and (2) provide an accessible methodology for the evaluation and visualization of bioerosion in archaeological bone using virtual anthropology techniques. We describe bioerosion in unedited virtual cross-sections and in 3D volume renderings. Furthermore, we reduced the need for time-consuming image segmentation by sequentially applying two noise-reducing, edge-preserving filters and using an image-display transfer function (colormap) that visualizes bioerosion and canal structure and density in 3D. In doing so we contribute a minimally destructive investigative tool for reconstructing post-mortem history in the archaeological record, and for the reliable screening of samples for further analysis.

\section{Material And Methods}

The dataset is based on 28 samples selected from five archaeological sites in the temperate European environment of Lower Austria dating from the Early Neolithic to Late Iron Age (Table 1). Studies have demonstrated intra-skeletal variation for diagenetic alteration, and that the cortex of long bones tends to best describe bioerosion (e.g., Booth, 2017; Dal Sasso et al., 2014; Jans et al., 2004). To facilitate comparison with previous research (e.g., Booth, 2017; Jans et al., 2004; White \& Booth, 2014), samples $1-2 \mathrm{~cm}$ thick were preferentially extracted from the anterior aspect of the proximal femoral diaphysis $(n=15)$ inferior to the surgical neck. Rib $(n=2)$, mandible $(n=1)$, skull $(n=2)$, and humerus $(n=1)$ fragments were also selected to evaluate the efficacy of the method on non-femoral samples (Supplementary Materials ESM1). Five cremated long bones and two faunal mammalian long bones were also sampled. Samples were extracted with a diamond wheel blade attached to a Dremel ${ }^{\circledR} 3000$ electric drill. The histological investigation was conducted using the well-established OHI (Hedges \& Millard, 1995; Millard, 2001), while the virtual assessment was completed using the newly developed VHI. 
Table 1

Provenance and number of 28 cortical bone samples by period: femora $(n=15+5$ cremated), ribs $(n=2)$, parietal $(n=2)$, humerus $(n=1)$, mandible $(n=1)$, faunal long bones $(n=2)$. For further details see Supplementary Materials ESM 1

\begin{tabular}{|c|c|c|c|c|}
\hline Site & $\begin{array}{l}\text { Sample date } \\
\text { range }\end{array}$ & Archaeological culture & Period & $\begin{array}{l}\text { No. of samples / } \\
\text { individuals }\end{array}$ \\
\hline Asparn-Schletz & $\begin{array}{l}5300-5000 \\
\text { BCE }\end{array}$ & Linear Pottery (LBK) & $\begin{array}{l}\text { Early } \\
\text { Neolithic }\end{array}$ & $7 / 7$ \\
\hline Gemeinlebarn A & $\begin{array}{l}2050-1650 \\
\text { BCE }\end{array}$ & Unterwölbling & $\begin{array}{l}\text { Early Bronze } \\
\text { Age }\end{array}$ & $6 / 6$ \\
\hline $\begin{array}{l}\text { Inzersdorf ob der } \\
\text { Traisen }\end{array}$ & 1200-900 BCE & Urnfield $\left(\mathrm{Ha} \mathrm{A}_{1}-\mathrm{Ha} \mathrm{B}_{1}\right)$ & $\begin{array}{l}\text { Late Bronze } \\
\text { Age }\end{array}$ & $4 / 4$ \\
\hline $\begin{array}{l}\text { Göttlesbrunn- } \\
\text { Arbesthal }\end{array}$ & 380-200 BCE & $\begin{array}{l}\text { Early / Middle La Tène (LT B } 1-L T \\
\left.\mathrm{~B}_{2} / \mathrm{C}_{1}\right)\end{array}$ & Late Iron Age & $7 / 5$ \\
\hline Roseldorf-Sandberg & 390-150 BCE & $\begin{array}{l}\text { Early / Middle La Tène (LT } B_{1}-L T \\
\text { C) }\end{array}$ & Late Iron Age & $4 / 4$ \\
\hline
\end{tabular}

Hedges et al. (1995) note the subjectivity inherent in rating samples with the $\mathrm{OHI}$ but found general agreement between observers within a single rating unit. This approach is applied here where we performed inter-rater reliability (IRR) tests between the two OHIs, between the two VHIs, and between the averaged OHls and the averaged VHIs using the Pearson correlation coefficient (PCC), joint probability of agreement (JPA), and limits of agreement (LOA). Overall IRR analysis, also known as interrater agreement or inter-observer reliability, is the degree to which there is agreement amongst independent observers rating the same phenomenon. The PCC is the linear correlation between two sets of data where it measures covariances, resulting in values ranging between -1 (highly uncorrelated) and +1 (highly correlated). JPA is the percentage of times that raters agree, and is the least robust measurement of IRR as it does not account for agreement based on chance. To compensate for this weakness, LOA was applied. This approach calculates the difference between each pair of observations with the mean value acting as the bias value $\pm 2 *$ standard deviation (Bland \& Altman, 1989). This type of analysis provides insight into how much random variation influences the ratings, as depicted in the Bland-Altman plots. Furthermore, to assess the true scope of variation of agreement, the JPA calculations were evaluated for an exact match (identical observations), an approximate match ( $\leq 0.5$ difference), and a general match ( $\leq 1.0$ difference. This approach captures the degree to which observers entirely agree (disregarding the principle of equifinality), and with applied thresholds for when observers somewhat and generally agree.

\section{Light microscopy (LM) and Scanning electron microscopy (SEM)}

Twenty-four samples were selected and embedded in a two-compound resin (Biodur® E1/E2) following a protocol for undecalcified bone (Schultz, 2001). The blocks were sectioned in the transverse plane with a Leica SP 1600 saw-blade microtome (Leica Microsystems) to a thickness ranging from 30 to $60 \mu \mathrm{m}$, then mounted to a glass slide with Histokitt (ROTI®) and covered with a glass top. A Nikon Eclipse Ni light microscope was used with $4 \times$, 10x, and 20x magnification under plane light, polarized light (XPL), and differential phase contrast light. Additionally, a lambda plate was used with XPL to visualize collagen. Micrographs were taken with a DS-Ri2 camera (Nikon) mounted to the microscope. All visualizations were conducted with NIA Elements BR Software (Nikon). Six samples were mounted on carbon planchets and examined with an IT 300 LAB6 (JEOL Ltd.) scanning electron microscope at low vacuum at $25.0 \mathrm{kV}$ under high magnification. Images were taken in backscatter electron mode.

\section{Oxford Histological Index (OHI)}

The $\mathrm{OHI}$ (Table 2) was developed to determine the percentage of bone unaffected by biogenic alteration within a single crosssection using thick, polished sections as evaluated by the application of an ordinal scale from zero, which indicates poor preservation without original features save for Haversian canals, to five, which indicates good preservation, like unaltered bone (Hedges et al., 1995; Millard, 2001) (Fig. 2). Jans et al. (2002) made two modifications to the OHI to provide a more detailed examination by (1) using thin sections, and (2) dividing the sample transversely, according to anatomy, into periosteal, 
endosteal, and midline sections, then assigning each an OHI (Jans, 2008). In the present study Jans et al.'s (2002) modifications to the $\mathrm{OHI}$ were used to quantify bioerosion in samples via LM and SEM. Two observers separately assessed the thin sections using the $\mathrm{OHI}$ (Supplementary Materials ESM 2).

Fig. 2 SEM-BSE images of two femora. (a) Complete destruction of microanatomy (OHI 0 ) by bioerosion with only Haversian canals $(\mathrm{H})$ remaining in sample S02. (b) Perfectly preserved microanatomy (OHI 5) with clearly identifiable osteocytes $(0)$ in sample GÖ04

\section{X-ray microtomography (microCT)}

The same samples from which thin sections were taken for LM and SEM were mounted in plastic cylinders supported with synthetic foam prior to microCT scanning. Scans were made at the University of Vienna Theoretical Biology imaging lab using a Zeiss/Xradia MicroXCT-200 or a Bruker/Skyscan 1272 microCT system, with image resolutions ranging from 4 to $10.9 \mu \mathrm{m}$ (isotropic voxel size). Further scanning specifications and parameters are outlined in the Supplementary Materials ESM 3.

\section{Image visualization}

Entire reconstructed image stacks were visualized with Amira software (v. 2020.2). When required, samples were rotated to align the stack in the transverse plane, in which virtual cross-sections were visualized. Two built-in filters were applied sequentially to the dataset, both of which function to reduce noise and detect edges. First, the Bilateral filter was applied in the direction of the canals (kernel size $=5$; similarity $=20$ ) for balancing smoothing while maintaining sharp edges (such as canals and MFD). Second, the Sobel filter was applied to the Bilateral filtered dataset. This step enhances intensity gradients, emphasizing important structural properties. A volume rendering was then applied to the composite filtered dataset to visualize the 3D volume. A volume rendering creates an image of a 3D dataset without segmentation by simulating the casting of light rays through the volume by assigning transmission and absorption parameters to each voxel (Schroeder et al., 2018; Thermo Scientific ${ }^{T M}$, 2018). In doing so the density information of the dataset is retained, unlike in an isosurface, which permits the visualization of important topographical details (Ryan \& Sukhdeo, 2016), such as textured canals and bioerosion. Edge 3d and Edge $2 \mathrm{~d}$ were selected for Shade Effects with the Lighting set to None. The volume renderings were visualized using the glow.col colormap.

Initially the volume rendering was visualized using two built-in colormaps (1) volrenWhite.am, and (2) glow.col. Colormaps determine the transparency and color values with which to display the image grey-scale values (Schroeder et al., 2018). The "white" colormap, for which intensity gradients below the colormap port minimum are rendered transparent, was found to be less informative than the "glow" colormap, whose artificial shading and edge coloring provides a good contrast range (Handschuh et al., 2010; Ryan \& Sukhdeo, 2016) that permits the visualization and differentiation of denser, unaltered bone from demineralized, bioeroded bone.

\section{Virtual Histological Index (VHI)}

The VHI (Table 2) was designed to closely reflect the $\mathrm{OHI}$; thus, the standard 0 to 5 ordinal scale was maintained. Evaluation of the originally stipulated anatomical and destructive features required some modification as microCT cannot visualize, for example, individual concentric lamellae or osteocytes. Features that can be visualized, such as Haversian and Volkmann canals, undifferentiated lamellae, and MFD were retained. Given the relative similarity of what could be found in the virtual slices in comparison to traditional histology, drastic modification of the OHI was not required. Following Jans et al. (2002) we assigned individual $\mathrm{OHIs}$ to the periosteal, endosteal, and midline regions then averaged the values to obtain a single VHI. Two observers separately assessed the scans using the VHI (Supplementary Materials ESM 2).

The initial examination included assessment of both the unfiltered virtual section and composite filtered section. Observations of the composite filtered section were inconsistent, likely because sections through a filtered volume image display too little of the structural information that can only be meaningfully visualized in 3D. Thus, the filtered virtual section was not used to calculate the VHI. 
All statistical analyses were performed in R (v. 4.0.2). All figures were formatted using GIMP software (v. 2.99.6), and the ScientiFig plugin (Aigouy \& Mirouse, 2013) for Fiji software (Schindelin et al., 2012).

\section{Results}

Twelve of the twenty-eight samples were selected to report what can be visualized in virtual cross-sections and volume renderings in comparison to what was identified in the thin section micrographs. The accompanying descriptions are included as an introduction to the identification of bioerosion in virtual images, and how it presents at each level of the VHI. This subset consists of samples from the femur, mandible, and humerus, and includes one faunal sample, a cremated sample, and a severely osteoporotic sample. Selected images are included in the text while the remaining can be found in the Supplementary Materials (ESM 4-10 \& ESM 12-27).

Table 2

Definitions of the Oxford Histological Index (OHI) (Hedges et al., 1995 \& Millard, 2001) and Virtual Histological Index (VHI)

\begin{tabular}{|c|c|c|c|c|}
\hline $\mathrm{OHI} / \mathrm{VHI}$ & $\begin{array}{l}\% \\
\text { Intact } \\
\text { Bone }\end{array}$ & $\begin{array}{l}\text { Description (thin } \\
\text { section) }\end{array}$ & Description (virtual section) & $\begin{array}{l}\text { Description (volume rendering, } \\
\text { glow.col colormap) }\end{array}$ \\
\hline 5 & $>95$ & $\begin{array}{l}\text { Very well } \\
\text { preserved, } \\
\text { indistinguishable } \\
\text { from fresh bone. }\end{array}$ & $\begin{array}{l}\text { Very well preserved, indistinguishable } \\
\text { from fresh bone: canals and lamellae } \\
\text { are clear, grey values are consistent } \\
\text { within and between slices. }\end{array}$ & $\begin{array}{l}\text { Canals are smooth, more yellow than } \\
\text { red, and in sharp contrast to void; no } \\
\text { evidence for bioerosion between } \\
\text { canals within the void. }\end{array}$ \\
\hline 4 & $>85$ & $\begin{array}{l}\text { Only minor } \\
\text { amounts of } \\
\text { destructive foci, } \\
\text { otherwise } \\
\text { generally well } \\
\text { preserved. }\end{array}$ & $\begin{array}{l}\text { Only minor amounts of destructive foci, } \\
\text { otherwise generally well preserved; } \\
\text { small patches of MFD present (darker } \\
\text { grey values). The canals and lamellae } \\
\text { are easily distinguished throughout the } \\
\text { stack. }\end{array}$ & $\begin{array}{l}\text { Canals are smooth, in sharp contrast } \\
\text { to void, and primarily yellow; small } \\
\text { patches of orange-red bioerosion } \\
\text { between canals, and streaks within } \\
\text { canals are evident, which may present } \\
\text { as small clusters. }\end{array}$ \\
\hline 3 & $>67$ & $\begin{array}{l}\text { Clear } \\
\text { preservation of } \\
\text { some osteocyte } \\
\text { lacunae. }\end{array}$ & $\begin{array}{l}\text { Destructive foci evident throughout } \\
\text { stack but more than half of the bone } \\
\text { remains unaffected; bioerosion spreads } \\
\text { beyond lamellae in patches but the foci } \\
\text { are still visible. }\end{array}$ & $\begin{array}{l}\text { Canals may be smooth and still } \\
\text { yellow in regions of minimal to no } \\
\text { bioerosion but are surrounded by } \\
\text { large clusters of bioerosion; some } \\
\text { void remains; in regions where } \\
\text { bioerosion clusters, canals are redder } \\
\text { and may be difficult to distinguish } \\
\text { from tunnelling. }\end{array}$ \\
\hline 2 & $<33$ & $\begin{array}{l}\text { Clear lamellate } \\
\text { structures } \\
\text { preserved } \\
\text { between } \\
\text { destructive foci. }\end{array}$ & $\begin{array}{l}\text { Destructive foci may still be present but } \\
\text { bioerosion now primarily presents in } \\
\text { wide swathes of dark grey values in } \\
\text { which lamellae are nearly } \\
\text { indistinguishable; in small unaffected or } \\
\text { less affected regions lamellae remain } \\
\text { distinguishable; there is more affected } \\
\text { bone than non-affected. }\end{array}$ & $\begin{array}{l}\text { Bioerosion is now pervasive } \\
\text { throughout. In heavily affected areas } \\
\text { canals are redder, no longer smooth, } \\
\text { and nearly indistinguishable from the } \\
\text { surrounding bioerosion. Canals that } \\
\text { are still visible may retain some } \\
\text { smoothness in small pockets where } \\
\text { bioerosion is weaker. }\end{array}$ \\
\hline 1 & $<15$ & $\begin{array}{l}\text { Small areas of } \\
\text { well-preserved } \\
\text { bone, or some } \\
\text { lamellar } \\
\text { structures } \\
\text { preserved by } \\
\text { pattern of } \\
\text { destructive foci. }\end{array}$ & $\begin{array}{l}\text { The majority of the stack is filled with } \\
\text { bioerosion; only the smallest patches of } \\
\text { MFD are distinguishable within a wide } \\
\text { swathe of dark grey values; in most } \\
\text { regions the lamellae have disappeared } \\
\text { or are only vaguely distinguishable. }\end{array}$ & $\begin{array}{l}\text { Canals are eroded, melted looking, } \\
\text { significantly more red than yellow, and } \\
\text { nearly indistinguishable from } \\
\text { bioerosion; the spongy texture of the } \\
\text { erosion is more evident than void. }\end{array}$ \\
\hline 0 & $<5$ & $\begin{array}{l}\text { No original } \\
\text { features } \\
\text { identifiable other } \\
\text { than Haversian } \\
\text { canals. }\end{array}$ & $\begin{array}{l}\text { Erosion is pervasive throughout and } \\
\text { hardly any unaffected bone remains; } \\
\text { lamellae are indistinguishable, only the } \\
\text { slightest outline remains within the } \\
\text { erosion; a small number of canals may } \\
\text { still be present or may be completely } \\
\text { obliterated. }\end{array}$ & $\begin{array}{l}\text { Canals are red, thin, eroded, stringy, } \\
\text { melted-looking, and present as an } \\
\text { indistinguishable spongy texture, } \\
\text { nearly or completely indistinguishable } \\
\text { from bioerosion. }\end{array}$ \\
\hline
\end{tabular}




\section{Sample 1. GÖ04/Femur (OHI 5/VHI 5) (Fig. 3)}

\section{OHI with LM}

No MFD can be found in the entire thin section. Many lacunae resemble fresh bone in their shape and condition, and osteocytes are clear; however, the majority display enlarged canaliculi indicative of Wedl tunnelling Type 2. A minority of Haversian canals are filled with a matrix that was not further identified. The circumferential lamellae of the periosteal layer are eroded while a layer of sediment covers the endosteal surface. There is a superficial area of brown staining along the periosteal surface. Collagen content is very good with weaker birefringence in areas along the midline and towards the periosteum. There is a small concentration of microfissures along the endosteal layer that follow the anatomy of a small number of osteons.

\section{Virtual cross-sections}

The bone is in nearly perfect condition with no bioerosion, only microfissures originating from the endosteal and periosteal surfaces, some of which travel around or through the concentric lamellae towards the midline, as seen in the thin sections. These lamellae are distinct, and grey values remain consistent throughout and between slices. The endosteal and periosteal circumferential lamellae have flaked off; matrix with higher density inclusions is attached to the surfaces with some infilling of canals as described in the thin sections.

\section{Volume rendering}

Canals are abundant, clearly defined, and more yellow than red, though not as yellow as canals of other unaffected samples. This likely results from the lower mineralization (lower density) associated with the younger age of this specimen (late juvenile) in comparison to, as will be seen, SB01 (Supplementary Materials ESM 4), which is a late adult. The canals are surrounded by void. The periosteal and endosteal borders are ragged where the circumferential lamellae have flaked off.

Fig. 3 Sample GÖ04, a late juvenile female. (a) Light micrograph of midline of a transverse histological thin section (interference phase contrast under 10(1x) magnification). (b) Single virtual transverse cross-section (1 voxel [6.7 $\mu \mathrm{m}]$ thick) through a microCT image showing midline and periosteal surface. (c) 3D volume rendering of entire virtual dataset showing midline

\section{Sample 2. SB01/Mandibular ramus (OHI 5/VHI 5) (Supplementary Materials ESM 4)}

\section{OHI with LM}

No MFD can be found in the entire thin section. There is reduced collagen content along the periosteal surface, but overall, collagen concentration is high. Enlarged lacunae and canaliculi, evidence of Wedl Type 2 tunnelling, are visible throughout the entire thin section. Both the periosteal and endosteal surfaces are in good condition, and osteocytes are numerous. There is no damage to the microstructure. Some sediment is visible along the surfaces of the trabeculae. A minority of the Haversian canals are filled with exogenous material that does not appear to be calcite.

\section{Virtual cross-sections}

The bone is in nearly perfect condition with no visible bioerosion. Grey values remain consistent within and between slices. The lamellae around Haversian canals are defined as are the cement lines that surround them. There are inclusions within a small number of canals and attached to trabeculae, as noted in the histology, which are not to be confused with bioerosion.

\section{Volume rendering}

The preservation is excellent. Canals are abundant, clearly defined, more yellow than red, and surrounded by void. The canals of this sample are more yellow than those of GÖ04 (also OHI/VHI 5), plausibly because of the increased mineralization of this sample, which also has cement lines (more highly mineralized cuffs surrounding concentric lamellae). 


\section{Sample 3. GÖ01/Femur (OHI 4.5/VHI 4.5) (Fig. 4)}

\section{OHI with LM}

The section is mildly affected by bioerosion with the highest concentration of MFDs present along the midline. Osteocytes are numerous. The circumferential lamellae are free of MFD. Overall collagen content is very high. Bacterial attack is concentrated primarily around and within the Haversian and Volkmann canals; these areas also have the highest concentration of enlarged canaliculi, indicative of Wedl Type 2 tunnelling. The periosteal surface is heavily eroded with brown staining along the periphery. Microfissures penetrate the bone from the periosteum, following the microanatomy. Microfissures are also present along the endosteal surface.

\section{Virtual cross-sections}

Bioerosion is minimal. Grey values are mostly consistent throughout and between individual slices; however, there is some loss of density (darker grey values), particularly along the midline. The lamellae surrounding Haversian canals are distinct but MFD is present in the form of small perforations clustering around the Haversian and Volkmann canals, and within the concentric lamellae, particularly along the midline. The smaller MFDs cluster to form larger MFDs. There is reduced density surrounding some canals. The inner and outer circumferential lamellae are eroded.

\section{Volume rendering}

The canals are smooth and yellow but are surrounded by small, orange-red thread-like clusters of MFD; upon zooming into the canals, thin areas of reduced density that present as reddish trails can be seen traversing the length of the yellow canals. These threads of bioerosion can be seen encircling and passing between canals. There are small perforations to some of the canals. Bioerosion clusters in the midline, though much void remains.

Fig. 4 Sample GÖ01, an early adult female. (a) Light micrograph of midline of a transverse histological thin section (polarized light and under 10(2x) magnification). (b) Single virtual transverse cross-section (1 voxel [8.0 $\mu \mathrm{m}]$ thick) through a microCT image showing midline, and periosteal and endosteal surfaces. (c) 3D volume rendering of entire virtual dataset showing midline

Sample 4. GE15/Femur (OHI 4/VHI 4.5) (Supplementary Materials ESM 5)

\section{OHI with LM}

The bacterial attack is arrested. The highest concentration of MFD is within the midline and endosteum; the trabeculae are affected and the periosteum mildly so. Microfissures follow the microanatomy along the periosteal surface. Collagen preservation is very good throughout the entire section. There is recrystallization within the Haversian systems, primarily along the endosteal surface with a milder manifestation along the midline.

\section{Virtual cross-sections}

Bioerosion is minimal. Grey values are mostly consistent throughout and between slices with minor density loss (darker grey values), particularly around the midline and towards the endosteal surface. Bioerosion is concentrated around Haversian systems with numerous MFDs present as small clusters of perforations that form speckled areas of demineralization surrounding some canals. However, the lamellae surrounding the Haversian canals are still visible. Some cement lines can be distinguished. The periosteal circumferential lamellae are eroded more so than the endosteal lamellae, which have also undergone microbial attack, as have the surfaces of the trabeculae. The microfissures that move from the periosteal surface towards the midline along the anatomy of the Haversian systems appear post-depositional as bioerosion does not follow them. There are some inclusions in canals near the endosteum.

\section{Volume rendering}


Though most of the canals have become more red than yellow, they remain distinct from the surrounding bioerosion. The canals in less affected areas are still rather yellow and easily distinguished from microbial tunnelling, such as towards the periosteum. Patches of void remain in these areas. Though microbial attack has not destroyed the canals, it is present throughout the sample, including along the surfaces of the trabeculae.

\section{Sample 5. S01/Femur (OHI 2.75 /VHI 3) (Fig. 5)}

\section{OHI with LM}

Bioerosion is inhibited. MFD is equally dispersed throughout the entire section. Collagen preservation is mediocre though it is better within the unaffected lamellae. There are many enlarged canaliculi and lacunae, evidence of type Wedl Type 2 tunnelling. Most of the canals are filled with recrystallization. The endosteal surface is not eroded, though the periosteal surface is damaged.

\section{Virtual cross-sections}

A moderate level of bioerosion is present. Canals can be distinguished throughout much of the bone. When they cannot be seen it is not due to bioerosion; the sample is an early adult and much of the endosteal circumferential lamellae remain where at this age, fewer secondary osteons have formed with cement lines. The periosteal circumferential lamellae are more heavily eroded. There are MFDs and patches of reduced density within the circumferential lamellae of the endosteal surface that connect with bioerosion surrounding Haversian systems. The lamellae of the Haversian canals are distinct within the areas of bone that remain relatively unaffected; the bioerosion, which presents as both MFD and patches of dark grey values, has primarily attacked the periosteum and the midline towards the periosteum. A large embedding artefact traverses the sample from the endosteum to the midline. Small patches of high density (white) material fill a few canals towards the endosteal surface and along the midline; the most external lamellae of the endosteum are also a higher density.

\section{Volume rendering}

Many canals are still yellow, particularly from the midline towards the periosteum, but all are surrounded by bioerosion; although the concentration of canals decreases towards the endosteum, this does not result from bacterial digestion, as noted in the virtual cross-sections, though other canals are bioeroded. Threads and tubules of reddish bioerosion surround them, many of which are variegated with red patches; in these areas the canals are also less smooth. It is not possible to visualize the interior of the canals to follow the paths of bioerosion down their lengths, as with GÖ01. Void remains in areas of minimal bioerosion, and within small regions of heavier bioerosion. The circumferential lamellae of the endosteal surface are clear in comparison to the periosteum where the lamellae are eroded.

Fig. 5 Sample S01, an early adult female. (a) Light micrograph of midline and endosteum of a transverse histological thin section (plane light under $4(1 \times)$ magnification). b) Single virtual transverse cross-section (1 voxel [8.0 $\mu \mathrm{m}]$ thick) through a microCT image showing midline, and periosteal and endosteal surfaces. c) 3D volume rendering of entire virtual dataset showing midline, and periosteal and endosteal surfaces

Sample 6. SB02/Humerus (OHI 2.5/VHI 2.5) (Supplementary Materials ESM 6)

\section{OHI with LM}

Bioerosion is inhibited. Areas remain unaffected with good preservation of the microstructure, particularly along the endosteal surface. However, there are MFDs throughout the entire section, and most of the lacunae are enlarged. Collagen preservation is mediocre to good. Microfissures follow the microanatomy, primarily along the periosteal surface, with one running through the entire section. Almost all the canals are filled with a matrix that looks like recrystallization. Both the periosteal and endosteal surfaces are strongly eroded.

\section{Virtual cross-sections}

Page $10 / 38$ 
The bone has undergone bioerosion in large irregular patches. Canals are present throughout the stack; the circumferential lamellae of the periosteal and endosteal surfaces have been shed. Bioerosion is present along the midline towards the periosteum more so than the endosteum. Large patches of bioerosion present as darker grey values; in these regions concentric lamellae are difficult or impossible to distinguish. In areas where bioerosion is arrested, MFD can be distinguished, and concentric lamellae remain visible. There is a thin microfissure moving from the endosteum into the midline.

\section{Volume rendering}

Canals are still present, but their quality varies between regions analogous to what is found in the virtual cross-sections. The canals to the right and towards the endosteum are denser (more yellow) than those to the left of the image. However, the betterpreserved canals are patched with red, and it is difficult to clearly visualize their interiors. The canals that have undergone heavier microbial attack are less dense, redder, and withered. It is difficult to distinguish the eroded anatomical canals from microbial tunnelling. Although the circumferential lamellae have been heavily eroded, the layer that remains is still relatively dense (yellower), though patched with red. Some void remains, particularly towards the right.

Sample 7. R03/Femur (OHI 1/VHI 1.75) (Supplementary Materials ESM 7)

\section{OHI with LM}

Bioerosion is present throughout the entire section. MFD concentrations are strongest along the midline towards the endosteal surface. A large area along the midline towards the endosteum remains mostly unaltered with unaffected lamellae still visible, though there are some MFDs around the Haversian canals. Within this area collagen content is very good and the lacunae remain a normal size. All canals and microfissures are filled with recrystallization. A large microfissure runs from the periosteal surface of the entire section through the histological anatomy, which may be the result of lichen penetration. Microfissures that follow the microanatomy travel from the periosteum into the midline. Sediment is attached to some areas of the periosteal surface.

\section{Virtual cross-sections}

The bone has undergone bioerosion in large patches. Canals remain, particularly in the midline area of arrested microbial attack, but bioerosion is pervasive throughout and between slices, particularly along the endosteum and towards the periosteum. Though bioerosion frequently attacks the concentric lamellae, rings of denser bone separate erosion from the canals. Along the midline where bone remains better preserved, the lamellae of Haversian systems are visible as are faint cement lines. Many of the canals are filled with dense (white) inclusions in areas of heavy and light bioerosion. Circumferential lamellae, particularly along the endosteal surface, are heavily affected. The outer layer of the endosteal surface is also denser. Two large microfissures encircle the midline where bioerosion is arrested, as noted in the histology. The periosteal circumferential lamellae are eroded but are slightly denser than the endosteal lamellae.

\section{Volume rendering}

Anatomical canals remain but their quality varies between regions analogous to what is found in the virtual cross-sections. Many of the better-preserved canals are patched with red, though others are almost completely red and appear transected where bacteria have digested the bony matrix longitudinally through the canal. Red bacterial tunnelling is evident throughout the volume, and in some regions presents as webs of fibrous red spirals. The circumferential lamellae along the endosteum are completely bioeroded. One of the large microfissures that runs transversely through the section is clearly visible.

\section{Sample 8. GE08/Femur (OHI 0.5/VHI 0.75) (Supplementary Materials ESM 8)}

\section{OHI with LM}

The bacterial attack is heavy throughout much of the section except for the periosteal surface. There is yellow staining along the periosteum along with enlarged canaliculi and lacunae. There is some remaining collagen in this area. The midline to the 
endosteal surface is heavily eroded. There is also some yellow staining along the endosteal surface. MFD is present along the circumferential lamellae. There are two embedding artefacts. Only Haversian canals are identifiable.

\section{Virtual cross-sections}

The bone has undergone bioerosion in large irregular patches. Anatomical canals remain but bioerosion is pervasive throughout and between slices. Only the smallest islands and trails of unaffected bone remain; the bioerosion is now so heavy that individual MFDs cannot be distinguished. Lamellae surrounding Haversian canals can only be distinguished from the surrounding interstitial lamellae because they have been, presumably, preferentially attacked by bacteria and thus present as thick rings of darker grey values. Both the periosteal and endosteal circumferential lamellae have been sloughed. Embedding artefacts travel transversely along a section of the periosteum as noted in the histology.

\section{Volume rendering}

As found in the virtual sections, bioerosion is pervasive throughout the sample. It is difficult to discern anatomical canals from microbial tunnelling; both are visualized as red channels surrounded by fibrous red webs. Slightly less affected, slightly more yellow canals can be recognized towards the left of the image.

Sample 9. GÖ03/Femur (OHI 0/VHI 0) (Supplementary Materials ESM 9)

\section{OHI with SEM}

The bacterial attack is strong. MFD is identifiable along the entire section with only Haversian canals remaining. A very small area of well-preserved bone remains along the endosteum; however, this surface is heavily eroded. Most of the canals are filled with an exogenous matrix, possibly recrystallization. The periosteal surface is also heavily eroded.

\section{Virtual cross-sections}

The bone has undergone extensive bioerosion and almost no unaltered bone remains. Small Howship's lacunae suggest incipient osteoporosis. Canals remain but bioerosion is extensive throughout and between slices, and several are filled with a dense (white) material, particularly along the periosteal surface towards the midline. The periosteal circumferential lamellae have been sloughed; some remain along the endosteal surface, which is also encrusted with inclusions as are canals along this border. Although the bioerosion affects the entirety of the sample, it is stronger (darker grey values) towards the periosteal surface where concentric lamellae can barely be distinguished if at all from the surrounding interstitial lamellae, and in a patch along the endosteal surface. Trails of lighter grey values where some lamellae of the Haversian systems can be seen, are interspersed amongst the generally heavy demineralization. In general, the bioerosion is now so heavy that individual MFDs cannot be distinguished.

\section{Volume rendering}

Bioerosion is pervasive throughout the sample. It is nearly impossible to discern anatomical canals from microbial tunnelling; everything is red and extremely fibrous as the bioerosion adheres to what remains of the canals like cobwebs.

\section{Sample 10. S04/Femur (OHI 0/VHI 0.25) (Fig. 6)}

\section{OHI with LM}

Macroscopic examination revealed the individual to be osteoporotic; this was confirmed by histology. Bacterial attack is heavy; only the Haversian canals are identifiable. There is no collagen preservation and there is recrystallization in most of the Haversian canals. Bioerosion is severe throughout the entire section. Exogenous sediment is attached to both the endosteal and periosteal surfaces with exogenous infilling along the endosteum.

\section{Virtual cross-sections}

Page $12 / 38$ 
The sample has undergone extensive bioerosion with almost no unaltered bone remaining. Canals remain distinct but bioerosion is extensive throughout and between slices; however, the bone is also porous and demineralized due to osteoporosis. Many of the canals exhibit clear evidence of resorption such as Howship's lacunae and heavily irregular borders. During senescence remodeling of Haversian systems, including smaller ones, results in the focal enlargement of canals and their coalescence, with a concomitant reduction in concentric lamellae (Seeman, 2013) as found in this sample, which should not be confused with bioerosion. Patches of bioerosion (dark grey values) are present as are MFDs, which, upon closer inspection, appear to surround canals; however, because the concentric lamellae are indistinguishable, partly due to age, it is difficult to see in all cases that the MFDs are concentrated around the canals. The circumferential lamellae of the periosteum and endosteum have been sloughed.

\section{Volume rendering}

The bone is so heavily demineralized by both osteoporosis and bioerosion that very little is visualized by the volume rendering using the glow.col colormap specifically, other than the faintest wisps of bone. Neither canals nor bioerosion are visible within the void.

Fig. 6 Sample S04, a late mature female. (a) Micrograph of midline and endosteum of a transverse histological thin section (lambda plate and 4(1.25×) magnification). (b) Single virtual transverse microCT cross-section (1 voxel [4.0 $\mu$ m] thick) showing midline, and periosteal and endosteal surfaces

\section{Sample 11. IN01/Cremated femur (OHI 4.75/VHI 4.5) (Fig. 7)}

\section{OHI with LM}

Macroscopic examination revealed the sample was cremated, which was confirmed by histology. It appears that there is no bioerosion, though discoloration makes the assessment difficult. Osteocytes are numerous and the lacunae are slightly enlarged. Howship's lacunae are also visible. There is recrystallization within the Haversian canals. The collagen signal is weak. Overall, the classic characteristics of concentric lamellae are lost as the matrix becomes homogeneous due to the cremation (Hunger \& Leopold, 1978; Schultz, 1986).

\section{Virtual cross-sections}

The analysis of the microCT images confirms that the bone was cremated; however, the evaluation was hindered by the inability to visualize certain anatomical features due to burning. Grey values are, save for high density (bright white) recrystallization, consistently a medium-dark grey throughout the stack. The periosteal circumferential lamellae are missing, though some remain along the endosteum. Canals can be distinguished throughout, though they appear smaller than usual by visual inspection. However, a morphometric assessment is required to verify this. It is demonstrated that burning at medium-tohigh/high temperatures results in shrinkage, cracking and crystallization (Boschin et al., 2015; Ellingham \& Sandholzer, 2020; Hanson \& Cain, 2007). Several long, narrow microfissures travel from both the periosteum and endosteum towards the midline; all are dense (whiteish), which may be crystallization. The lamellae surrounding Haversian canals are obscured by burning but are more clearly visible towards the endosteum and along the midline than the periosteum. That they remain visible may be due to the slightly denser cement lines that are visible around some Haversian systems. What may be Howship's lacunae can also be seen.

\section{Volume rendering}

Cremated bone is more difficult to visualize with the glow.col volume rendering. The canals are red and have the appearance of translucent melted wax. Although there appears to be little to no bioerosion in the virtual section, the demineralization caused by cremation results in a melted appearance.

Fig. 7 Sample IN01, an adult-mature female. (a) Light micrograph of midline and endosteum of a transverse histological thin section (plane-polarized light and 10(1x) magnification). (b) Single virtual transverse microcT cross-section (1 voxel [10.9 $\mu \mathrm{m}]$ 
thick) showing midline, and periosteal and endosteal surfaces. (c) 3D volume rendering of entire virtual dataset showing midline and periosteum

Sample 12. R04/Faunal long bone fragment (OHI 3.5/VHI 3) (Supplementary Materials ESM 10)

\section{OHI with LM}

This bone was macroscopically identified as non-human. There is a clear pattern of bioerosion with MFDs visible in patches throughout the entire section but bioerosion is inhibited. Under polarized light a thick, high-density band can be seen along the periosteum and a thinner band along the endosteum. There is brownish staining along both the periosteal and endosteal surfaces. Haversian canals are visible in the histology, and the canaliculi are slightly enlarged. In areas without MFD the lacunae are typical in size. Collagen preservation is poor even in the islands of bone that are free of MFD.

\section{Virtual cross-sections}

The bone has undergone moderate bioerosion. Some circumferential lamellae remain along the endosteum and periosteum; both surfaces have light grey, higher density bands as noted in the histology. Bioerosion manifests in patches relatively evenly throughout and between slices though it is slightly more concentrated along the midline. Although MFDs have spread throughout the sample, they remain distinct and do not generally present as undifferentiated dark grey patches. There are several embedding artefacts that primarily travel longitudinally from the periosteum. There are few canals, which is expected for plexiform animal bone, and the few Haversian lamellae that are visible are difficult to distinguish. There is potentially also osteon banding between two longitudinal microfissures below the transverse crack along the midline.

\section{Volume rendering}

As there are few Haversian systems to visualize, canals are not represented in the volume rendering despite the intermediate $\mathrm{OHI}$ value. The small number of Haversian canals that are visible present towards the endosteal surface, which would be expected for animal bone, as larger concentrations of Haversian systems are often found towards the endosteum as plexiform bone is found towards the periosteum in animals belonging to Artiodactyla (Bradfield, 2018). Bioerosion is evident throughout the sample, and in areas of arrested erosion there is void without canals, particularly along the midline. The embedding artefacts are clearly visible.

\section{Statistical Results}

The following results (Table 3 ) show that exact matching within each histological index is at least $54 \%$ but diminishes across all observations. However, it is useful to also assess approximate and general observational matches, as the histological indices are categorical across several criteria. This approach elucidates the rate of approximate agreement of minimal variation and minor variation. Assessing for these minimal disagreements $(\leq 0.5)$ demonstrates a significant increase in observation agreement for both $\mathrm{OHI}$ and $\mathrm{VHI}$ ratings. Furthermore, a general matching with a threshold of $\leq 1.0$ between observations demonstrates a significant increase of all categories, with a minimum of $93 \%$ agreement.

Table 3

Joint-probability of Agreement calculations between $\mathrm{OHI}$ observations, $\mathrm{VHI}$ observations, and across all observations. Each set of calculations were analysed for an exact match, approximate match (within $\leq 0.5$ ), and general match (within $\leq 1.0$ )

\begin{tabular}{|llll|}
\hline \multicolumn{3}{|c|}{ Joint-probability of agreement $(n=28)$} \\
\hline & Exact Match & Approx. Match $(<=0.5)$ & General Match $(<=1)$ \\
\hline OHI & $54 \%$ & $61 \%$ & $96 \%$ \\
VHI & $61 \%$ & $82 \%$ & $96 \%$ \\
\hline Overall & $21 \%$ & $39 \%$ & $93 \%$ \\
\hline
\end{tabular}

Page 14/38 
The results of our PCC analyses (Table 4) demonstrate a strong positive (0.94) correlation between the OHI as rated by two observers, a stronger positive (0.96) correlation between the VHI as rated by two observers, with a strong correlation overall (0.97) between the mean values of $\mathrm{OHI}$ and $\mathrm{VHI}$ observations. To account for observational agreement by chance, LOA analysis was performed. As histological indices are based on multiple criteria with multiple descriptive indicators, the problem of equifinality arises. This approach helps address the chance to which observers agree and assesses agreement based on genuinely similar observations using the same rating scale. The LOA analysis (Table 5) demonstrates that for the OHI, observer 1 measures slightly biased (0.25), whereas for VHI observer 2 measures negligibly biased (-0.02). These negligible differences indicate that both observers produce relatively similar results, with a trend of observer 1 rating marginally higher observations (4s and $5 \mathrm{~s}$ ) and observer 2 rating slightly lower observations (1s and $2 \mathrm{~s}$ )(Fig. 8a \& b).

Table 4

Pearson Correlation Coefficient calculations between $\mathrm{OHI}$ observations, VHI observations, and the mean values of both $\mathrm{OHI}$ and $\mathrm{VHI}$ observations as the overall analysis

\begin{tabular}{|ll|}
\hline Index & Pearson Correlation Coefficient \\
\hline OHI & 0.94 \\
\hline VHI & 0.96 \\
\hline Overall & 0.97 \\
\hline
\end{tabular}

Table 5

Limits of Agreement calculations of $\mathrm{OHI}, \mathrm{VHI}$, and the mean values of both $\mathrm{OHI}$ and $\mathrm{VHI}$ observations as the overall analysis

\begin{tabular}{|llll|}
\hline \multicolumn{4}{|c|}{ Limits of Agreement } \\
\hline & Average Difference & Lower & Upper \\
\hline OHI & 0.25 & -1.1244 & 1.62437 \\
\hline VHI & -0.02 & -1.0888 & 1.05304 \\
\hline Overall & -0.04 & -0.9681 & 0.87885 \\
\hline
\end{tabular}

A $95 \%$ confidence interval is used to determine the limits of agreement across observations (see Bland \& Altman, 1989). For the $\mathrm{OHI}$, the systematic difference is greater than the $\mathrm{VHI}$ observations (Fig. $8 \mathrm{a} \& \mathrm{8b}$ ) as indicated by the upper and lower limit ranges. One observation (GÖ25) falls outside the LOA for the OHI assessment (Fig. 9a); however, this is the only differences where the observers rated a specimen significantly different. Similarly, VHI observations were consistently matching and observer bias is distributed evenly with 1 observation falling outside the limits of agreement: GE08 where observer 1 rated the sample higher than observer 2 (Fig. 9b).

Furthermore, the trend across observations is similar for both the $\mathrm{OHI}$ and $\mathrm{VHI}$ where observer 1 tends to rate more specimens higher and observer 2 tends to rate more specimens lower (Fig. 9c). However, the $\mathrm{OHI}$ illustrates a slightly more accentuated slope $(y=0.0639 x+0.0753)$ compared to the VHI $(y=0.0537 x-0.1671)$, demonstrating the minor differences in observations between the extreme ratings. This further shows that the observers are more prone to rate at either end of the scale and with minimal inherent bias in one observer compared to the other.

Fig. 8 Frequency of a) OHI ratings per observer. b) VHI ratings per observer

Fig. 9 Bland-Altman plot (a) Differences between OHI observations. (b) Differences between VHI observations. (c) Differences between all observations 
It has previously been noted that archaeological samples fall into a bimodal distribution on the $\mathrm{OHI}$ scale, between extensive microbial attack and its absence (Kendall et al., 2018; Millard, 2001), which "suggests that histological alteration tends to go more or less to "completion" if it happens at all" (Hedges et al., 1995, p. 203). We have found a similar bimodal distribution for this temporally diverse dataset for both the $\mathrm{OHI}$ and VHI (Supplementary Materials ESM 11).

\section{Discussion}

The IRR results demonstrate that the $\mathrm{VHI}$ evaluation of virtual sections is congruent with the $\mathrm{OHI}$ rating of histological thin sections. As noted, certain structures taken into consideration by the $\mathrm{OHI}$, such as individual concentric lamellae, cannot be differentiated, nor can structures smaller than $1 \mu \mathrm{m}$ (e.g., osteocytes or their lacunae) be visualized without synchrotron-based microCT (Andronowski et al., 2017a,b), but undifferentiated concentric lamellae, and features such as shallow pits and tunnels can be seen with lab-based microCT. Moreover, our inability to visualize osteocytes and their lacunae may result from a contrast-to-resolution issue during the scan. Thus, the VHI is able to describe the level of bioerosion that a sample has undergone, specifically that which results from bacterial attack. It may be possible that non-MFD bioerosion can be detected and differentiated with microCT images; however, the samples included in this study almost exclusively exhibited MFD, and not Type 1 Wedl-, nor cynobacterial tunneling. Importantly, in other respects the virtual images are also consistent with what has been qualitatively described in conventional thin sections.

Jans et al. (2002) specify five categories of diagenetic alterations as visualized via histology (1) presence and type of MFD; (2) presence of inclusions (e.g., sand, fungi, framboids); (3) presence of infiltrations, such as stains exogenous to the bone matrix; (4) presence of microfissures, and (5) birefringence intensity (see Fig. 1b). We found that MFD can be clearly visualized both in virtual sections and in 3D volumes, and can, moreover, be virtually measured (as can anatomical features) to refine their identification by size (Fig. 10). Such measurements are possible due to the pixel-size calibration inherent in microCT scans. In badly affected samples it is difficult to ascertain which type of tunnelling is present, as the bioerosion presents as large dark grey patches. However, this problem is also encountered with thin section micrographs of badly preserved samples, and, moreover, though morphologically distinct, different MFDs are very likely, "all aspects of the same type of bacterial attack, differing only in tissue microarchitecture and local hydrology” (Turner-Walker, 2019, p. 35). We were also unable to visualize the Type 2 Wedl tunnels diagnosed via histology. This is likely due to the small size of the tunnels, which although they may be long, are not thick enough to be visualized at the resolution we used.

\section{Fig. 10 Virtual measurements of MFD and Haversian canal in midline of a single virtual transverse cross-section (1 voxel [8.0 $\mu \mathrm{m}]$ thick) of femoral sample GÖ01}

We agree with Booth et al. (2016) that although inclusions can be observed based on differences in density (grey levels) and texture, no further identification can be made. Infiltrations such as stains are more difficult to distinguish in microCT images. While it may be possible to detect a stain after its having been recognized through histology, it is not immediately apparent using virtual images alone that a change in grey values results from, for example, the impregnation of organic or inorganic substances as manifested macro- or microscopically as a stain, or if changes to the grey values result from demineralization caused by bacterial attack. Furthermore, while dissolution and recrystallization of HAp can be visualized as changes in grey values, it is not possible to determine the uptake or exchange of specific materials like uranium or fluorine, or nitrogen content as identified via energy dispersive X-ray spectroscopy, nor can microCT visualize the hypermineralized cuffs surrounding tunnels that result from mineral reprecipitation as is specifically achievable with SEM (Kendall et al., 2018; Turner-Walker \& Syversen, 2002). Microfissures recognized in histological sections can be clearly detected in virtual sections; it is also possible to determine if the microfissures are post-depositional, embedding artefacts, or result from excavation damage. Birefringence intensity cannot be assessed, though collagen content can be visualized with staining procedures not employed in this study (Handschuh et al., 2017). Lastly, virtual evaluation of sub-micron spongiform porosity (0.1-1 $\mu \mathrm{m}$ in diameter), a common form of tunnelling in archaeological bone (Turner-Walker, 2012; Turner-Walker et al., 2002), requires SR-microCT (Caruso et al., 2020).

As concerns qualitative descriptions of how bacteria invade bone, we once again find congruence between microscopy and virtual imaging. Yoshino et al. (1991) described regions heavily affected by bacteria and fungi as potentially corresponding to

Page 16/38 
low X-ray density. As noted, areas of low density (dark grey values) that result from mineral dissolution and redistribution (Hackett, 1981) correspond to MFD in the virtual sections. Yoshino et al. (1991) also reported 5-10 $\mu$ m in diameter vacuoles surrounding circumferential and Haversian lamellae, while Jackes et al. (2001) describe the orientation of MFDs along circumferential lamellae and the axis of Haversian systems. These vacuoles, or MFDs, were also visible in virtual sections within and surrounding the lamellae of Haversian systems and in circumferential lamellae. It has also been suggested that bacterial attack and chemical demineralization are impeded by cement lines (Kendall et al., 2018; Turner-Walker, 2012; TurnerWalker et al., 2002). We may be visualizing this in samples such as GE08 (Supplementary Materials ESM 8) where bioerosion appears to specifically attack the undifferentiated concentric lamellae, while in some regions of S01 (see Fig. 5) bioerosion seems to affect the interstitial lamellae, surrounding but not penetrating the concentric lamellae. However, there were no observable cement lines in sample S01. Moreover, after a certain point, when bioerosion has become severe, even if only within patches as with SB02 (Supplementary Materials ESM 6), it is not possible to distinguish where bacterial attack begins or ends. Further research is thus required to confirm that bacterial attack is curbed by cement lines.

The volume rendering depictions of bacterial attack are worth particular mention as we were able, using the "glow" colormap, to visualize in 3D what has previously only been reported in 2D. It is hypothesized that bacteria disseminate through and enlarge the canalicular network, accessing collagen via Haversian and Volkmann canals (Hackett, 1981; Kendall et al., 2018; TurnerWalker, 2019). Turner-Walker (2012) and Yoshino et al. (1991) also describe the occupation of Haversian canals by bacteria. While it is not possible to visualize bacterial attack on the canalicular network due to restrictions imposed by scan resolution, we saw evidence of bacterial attack within the canals. Sample GÖ01 (Fig. 11) provided a particularly interesting volume in which fine red trails follow the interior length of well-preserved yellow canals, the colors reflecting differences in X-ray density. These are arguably the demineralized traces of bacteria that have entered the Haversian and Volkmann canals, consumed their soft tissues (i.e., blood and lymphatic vessels, and nerve fibers), and then attacked the more mineralized concentric and interstitial lamellae. Indeed, we see further evidence of bioerosion in the form of miniscule holes that penetrate some canals (Fig. 11), and as endocasts of bacteria which take the form of narrow, almost translucent red tunnels through the bone matrix. Jackes et al. (2001) also described what they believe to be the endocasts of bacterial chains as varied trajectories of circumscribed tunnels, visible in both longitudinal- and cross-sections. These tunnels present in volume renderings (e.g., Supplementary Materials ESM 5) as thin red channels that migrate through the bone, often at first in the direction of the Haversian canals but also in numerous directions. Depending on the severity of the erosion, they may present as discrete spirallike red tunnels distinct from the anatomical canals to an almost cobweb-like film that veils degraded canals (e.g., Supplementary Materials ESM 6), or even as an amorphous spongy texture (e.g., Supplementary Materials ESM 8) in the most poorly preserved samples.

\section{Fig. 11 3D volume rendering showing MFD tunneling (a), red trails of bioerosion (b) and miniscule holes in Haversian canals (c) in midline of femoral sample Gö01}

Jackes et al. (2001) noted that in previously published figures (e.g., Bell, 1990; Garland, 1987; Grupe \& Dreses-Werringloer, 1992; Hackett, 1981; Piepenbrink, 1986; Schultz, 1986) that illustrate MFD, the magnification was not high enough to clearly visualize the bioerosion and that the cross-sections these authors used resulted in a view that resembles grape clusters, which do not match what can be visualized using longitudinal sections such as those published by Bell (1990). These grape-like clusters are also visible in the 3D volume of GÖ01 (see Fig. 4). When the volume is viewed from different angles it can be seen that these clusters are actually tunnels that run longitudinally and at angles through the bone (Fig. 12). This visualization is similar to, but clearer than what is seen at very high magnification ( $>600 \times)$ with microscopy. MicroCT is a valuable tool in this respect, as it permits the selection and visualization of any location within a sample in any orientation. Samples scanned, for example, in the coronal plane can be virtually resliced to the transverse plane. The virtual dataset can also be rotated to align with any anatomical plane using landmarks. We chose to reslice our samples for assessment in the orientation of traditional thin sections for two reasons (1) to facilitate comparison with traditional micrographs, and (2) 3D visualization of the canals and erosion in planes that do not follow the orientation of the Haversian systems made it difficult to assess bioerosion patterns in a three-dimensional sample. Furthermore, samples can be virtually cropped to visualize smaller volumes. The capacity to reslice, 
rotate, and virtually crop or dissect samples, repeatedly if desired, is specifically achievable with virtual but not conventional histologic methods.

\section{Fig. 12 3D volume rendering showing MFD tunneling in femoral sample GÖ01}

According to both Dal Sasso et al. (2014) and Booth et al. (2016) individual slices within a stack are representative of the sample, or entire femoral midshaft, and thus the $\mathrm{OHI}$ applied to a single transverse cross-section may be "considered representative of the sample itself" (Dal Sasso et al., 2014, p. 37). We assessed the complete stack of virtual sections from microCT images and confirmed that within a given stack that individual slices are homogeneously affected by bioerosion. While it appears probable that this holds true for the entire midshaft, further research should assess different regions of the femoral diaphysis to confirm homogeneity within the entire shaft, particularly when staining is present in patches.

Effects of skeletal sample region: Using microCT Dal Sasso et al. (2014) found that skull, rib, and femur fragments present with different levels of bioerosion with femoral samples being the best preserved, and further suggest that the poorer preservation of rib and skull bone microstructure results from the higher volume of trabecular bone and porosity associated with the latter, which can be more heavily affected by inclusions and MFD. In the current study we had both femoral and rib samples from only two individuals (GÖ01/GÖ24 and GÖ04/GÖ25), none of which were badly affected by bioerosion; thus, we can neither confirm nor refute their findings. Nevertheless, our research suggests that, although the femoral diaphysis, which has a thick cortical layer, is preferred for visualizing canal structure and Haversian systems, the VHI can also be applied to mandibular, cranial, and rib samples. However, the volume renderings can be more difficult to interpret. For example, mandibular sample SB01 (Supplementary Materials ESM 4), an OHI/VHI 5, has numerous anatomical canals that can be clearly visualized within the void, while subadult cranial sample SB04 (Supplementary Materials ESM 12), also an OHI/VHI 5, which has fewer canals, is not so clearly visualized. Sample R02 (Supplementary Materials ESM 13) (OHI/VHI 2), also a cranial fragment, but this time of an adult, provides a clearer image; however, there is higher density recrystallization around the canals and trabeculae of this sample, which facilitates visualization. Humeral fragment SB02 (Supplementary Materials ESM 6) (OHI/VHI 2.5) of a juvenile with numerous canals also provides a clear visualization. Rib samples GÖ24 (Supplementary Materials ESM 14) (OHI/VHI 4.5) and GÖ25 (Supplementary Materials ESM 15) (OHI 4/VHI 5), which have numerous canals (particularly GÖ24) can be clearly visualized but are not as easy to interpret as femoral samples.

Effects of cremation: We suggest that some cremated samples can be evaluated with the VHI. However, the degree of burning may affect how easily this can be done. As noted in the assessment of IN01 (see Fig. 7), cremation results in the homogenization of grey values, which obscures anatomical features like concentric lamellae. Samples that have been cremated at presumably higher temperatures, such as IN04 (Supplementary Materials ESM 16) are more difficult to evaluate. Lemmers et al. (2020) conducted experiments to ascertain the visibility of bioerosion in histological sections of bone that have been cremated, concluding that it can be identified in burnt remains. Thus, the classical histological analysis provides good results; however, further experiments are required assessing the effects of burning on bioeroded versus uneroded remains in microCT images to better understand how bioerosion may be visualized in cremated remains. However, given the high concordance between the VHIs and OHIs of cremated samples, as demonstrated by the IRR, we included them in the dataset. Interestingly, we found that although microanatomy could still be visualized in virtual sections, even if poorly, the volume renderings of cremated samples were often, but not always extremely poor, even in instances of an OHI 5. Sample R01 (Supplementary Materials ESM 17) provided a significantly clearer 3D visualization than IN01 (see Fig. 7), IN02 (Supplementary Materials ESM 18) or INO3 (Supplementary Materials ESM 19). Specific calibration of the microCT scans to measure absolute mineral density, or more particularly calcium content, may help to better visualize cremated remains (Handschuh et al., 2017). Lastly, previous research suggests that cremation results in bone shrinkage, cracking and crystallization (Boschin et al., 2015; Ellingham \& Sandholzer, 2020; Hanson \& Cain, 2007). While we are able to visualize dense (bright white) infilling in the scans, which may be recrystallization, as well as cracking, morphometric analysis is required to confirm shrinkage.

Effects of pathological alteration: With any histological evaluation familiarity with microanatomical structures is required to identify their presence and destruction by bioerosion. It is also important to have an understanding of, for example, hematologic and metabolic bone disease, and how these features are visualized in microCT images. Pathological alterations

Page $18 / 38$ 
affect the visualization and interpretation of skeletal remains, including, we found, in volume renderings using the "glow" colormap. While it was still possible to apply the VHI to the virtual sections of sample S04 (see Fig. 6), a late-mature female, it was immediately clear that this individual was severely osteoporotic. The volume rendering, using the "glow" colormap, of heavily demineralized samples such as S04 visualizes very little. Thus, for heavily demineralized, or samples characterized by pathological changes, it is worthwhile to try a variety of colormaps to test which can be used to best visualize canal structure and bioerosion in 3D.

Faunal samples: Again, although applying the $\mathrm{VHI}$ to non-human samples yielded similar ratings to the $\mathrm{OHI}$, they too were less clearly visualized in 3D. As noted in the Results, little was visualized in faunal sample R04 (Supplementary Materials ESM 10) $(\mathrm{OHI} 3.5 / \mathrm{VHI} 3)$, tentatively identified as belonging to Artiodactyla, which is potentially due to the paucity of Haversian canals in bone of this mammalian order. Sample GÖ14 (Supplementary Materials ESM 20), an ovicaprid humerus (OHI 3.5/VHI 4.25), also yielded a poor volume rendering in which very little was visualized, consistent with both the SEM and virtual sections.

\section{Conclusion}

A strong correlation between histotaphonomy and virtual methods provides the first steps towards substantiating microCT for assessing biogenic micro-taphonomy in archaeological bone. Though the evaluation of thin sections via light microscopy or SEM remains the best means to identify the presence and type of chemical and microbial diagenesis (e.g., collagen leaching using lambda filters, Wedl MFDs, and hypermineralized cuffs) affecting a sample, visualization with these methods entails time consuming, labor intensive, multi-step processes during any step of which artefacts may be accrued. Numerous 30-55 $\mu \mathrm{m}-$ thick slices must be sectioned with a microtome from an embedded sample with small areas of each section assessed individually. Moreover, transverse histological thin sections permit visualization in only a single direction. Although SR-microCT (Caruso et al., 2020), which can provide superior resolution, has also been used, it is not as readily accessible as lab-based microCT scanners, the costs of which are within the reach of start-up grants. Using microCT several fragments of bone (or, if small enough, an entire skeletal element) can be scanned at once or in automated batches. While scan acquisition may take some hours, once scanned and reconstructed, the entire sample can be rather quickly and easily visualized in 3D using a colormap that reduces the need for time-consuming segmentation. Furthermore, specimens do not require embedding, sectioning, and polishing, though samples that have already been embedded can be scanned without a resultant decrease in the clarity of the visualization of microanatomy. The method can thus be applied, for example, to old samples from museum collections without the need for further destructive sampling.

This study has demonstrated that microCT can be used as a complementary method to histology for the rapid, accessible evaluation of bioerosion in archaeological bone, and for the screening of samples for further, more destructive analyses. The $\mathrm{VHI}$ method, like the $\mathrm{OHI}$, remains subjective; however, the strong IRR results suggest that this is not a major problem. Further research may amalgamate the quantitative methods of Turner-Walker \& Syversen (2002) with virtual techniques to improve accuracy and reproducibility. We also recommend that future analyses explore the effects of cremation on the visualization of bioerosion, the visibility of Wedl- and cyanobacterial tunneling in virtual sections, and the applicability of other histological indices to microCT scan images.

\section{Declarations}

Declaration of conflict of interest: The authors declare no competing interests.

Authors' contributions: K.M. and K.S.D.C. conceived of and contributed equally to the study. B.M. supervised the study. K.S.D.C., K.M., and D.B. performed the formal analyses. E.W-K. and M.T-N. provided skeletal materials and/or interpreted archaeological or anthropological information. K.M. \& K.S.D.C. performed the osteological analysis. B.M. and K.M. microCT scanned the samples. K.M. performed all histological lab work, and interpretations with the aid of D.B. K.M. created all histological micrographs. K.S.D.C. created all microCT visualizations. A.MC. performed and created all statistical analyses and plots. B.M.

Page 19/38 
contributed technical expertise regarding scanning and visualizations. D.B., M.T-N., and M.G. contributed to the histological and anatomical interpretation. K.S.D.C. and K.M. wrote the manuscript with input from all co-authors.

\section{Author affiliations:}

Department of Evolutionary Anthropology, University of Vienna. 1 Djerassiplatz, 1030, Vienna, Austria.

Kirsten Mandl, Kellie Sara Duffett Carlson, Maria Teschler-Nicola, Martin Grassberger

Historical Archaeology, Austrian Archaeological Institute (ÖAl), Austrian Academy of Sciences (ÖAW), Franz Klein-Gasse 1, 1190, Vienna, Austria.

Kirsten Mandl, Estella Weiss-Krejci

Integrative Prehistory and Archaeological Science (IPAS), Department of Environmental Sciences, University of Basel. Spalenring 145, 4055, Basel, Switzerland

David Brönnimann

Faculty of Medicine, Sigmund Freud University. Freudplatz 3, 1020, Vienna, Austria.

Martin Grassberger

Department of Anthropology, Natural History Museum (NHM), Vienna. Burgring 7, 1010, Vienna, Austria.

Maria Teschler-Nicola

Department of Prehistory and Historical Archaeology (UHA), University of Vienna. Franz Klein-Gasse 1, 1190, Vienna, Austria. Estella Weiss-Krejci

Department of Evolutionary Biology Unit for Theoretical Biology, University of Vienna. Djerassiplatz 1, 1030, Vienna, Austria Brian Metscher

Corresponding authors: Correspondence to Kirsten Mandl and Kellie Sara Duffett Carlson 
Funding: This paper is part of a dissertation project and sponsored by the Vienna Doctoral School of Ecology and Evolution (VDSEE) 2021-Completion Grant of the University of Vienna awarded to K.M. Travel and consumables for thin-section preparation were funded by the DEEPDEAD project (Deploying the Dead: Artefacts and Human Bodies in Socio-Cultural Transformations) under the HERA Joint Research Programme "Uses of the Past" (UP) [Collaborative Research Project (CRP) no. 15.055] and the European Union's Horizon 2020 research and innovation programme under grant agreement No. 649307.

Acknowledgments: K.M. would like to thank Cordula Portmann, and especially Magdalena Müller-Gerbl, Peter Zimmermann, Mirelle Toranelli, and Andreas Ochsenbein from the Anatomy University Basel, Switzerland for training and support during thinsection preparation. Thanks are also extended to Maciej Karwowski, Jarosław M. Czubak, Michaela Fritzl, Franz Pieler, Karin Wiltschke-Schrotta, and the Austrian Federal Monuments Office for providing the archaeological samples. We kindly thank Mihaela Pavličev for granting access to the microCT scanners at the Unit for Theoretical Biology in the Department for Evolutionary Biology at the University of Vienna. Scanning electron microscopy was performed at the Core Facility of Cell Imaging and Ultrastructure Research (CIUS), University of Vienna, member of the Vienna Life-Science Instruments; we therefore kindly thank Daniela Gruber and Siegfried Reipert. Thanks are extended to Irene Lichtscheidl and her team from the CIUS facility for her major support and for providing the light microscope. K.M. and K.S.D.C. would particularly like to thank Marishka, Lilly, and Grögar, without whom this paper would not be possible. We would like to thank Suzanne Freilich for comments and suggestions. Lastly, we would also like to thank all anonymous reviewers for their comments.

Availability of data and material: All original data are available in the online supplementary information

Code availability: Not applicable

Ethics approval: Not applicable

Consent to participate: Not applicable

Consent for publication Not applicable

\section{References}

1. Aigouy, B., \& Mirouse, V. (2013). ScientiFig: a tool to build publication-ready scientific figures. Nature Methods, 10(11), 1048. https://doi.org/10.1038/nmeth.2692

2. Andronowski, J. M., Pratt, I. V., \& Cooper, D. M. L. (2017a). Occurrence of osteon banding in adult human cortical bone. American Journal of Physical Anthropology, 164(3), 635-642. https://doi.org/10.1002/ajpa.23297.

3. Andronowski, J. M., Mundorff, A. Z., Pratt, I. V., Davoren, J. M., \& Cooper, D. M. L. (2017b). Evaluating differential nuclear DNA yield rates and osteocyte numbers among human bone tissue types: a synchrotron radiation micro-CT approach. Forensic Science International Genetics, 28, 211-218. https://doi.org/10.1016/j.fsigen.2017.03.002.

4. Baier, W., Mangham, C., Warnett, J. M., Payne, M., Painter, M., \& Williams, M. A. (2019). Using histology to evaluate micro-CT findings of trauma in three post-mortem samples - First steps towards method validation. Forensic Science International, 297, 27-34. https://doi.org/10.1016/j.forsciint.2019.01.027.

5. Balzer, A., Gleixner, G., Grupe, G., Schmidt, H. L., Schramm, S., \& Turban-Just, S. (1997). In vitro decomposition of bone collagen by soil bacteria: the implications for stable isotope analysis in archaeometry. Archaeometry, 39(2), 415-429. https://doi.org/10.1111/j.1475-4754.1997.tb00817.x.

6. Bell, L. S. (1990). Palaeopathology and diagenesis: an SEM evaluation of structural changes using backscattered electron imaging. Journal of Archaeological Science, 17(1), 85-102. https://doi.org/10.1016/0305-4403(90)90016-X.

7. Bell, L. S., Skinner, M. F., \& Jones, S. J. (1996). The speed of post mortem change to the human skeleton and its taphonomic significance. Forensic Science International, 82(2), 129-140. https://doi.org/10.1016/0379-0738(96)01984-6. 
8. Bland, J. M., \& Altman, D. G. (1986). Statistical methods for assessing agreement between two methods of clinical measurement. The Lancet, 327(8476), 307-310. https://doi.org/10.1016/S0140-6736(86)90837-8.

9. Booth, T. J. (2016). An investigation into the relationship between bacterial bioerosion and funerary treatment in European archaeological human bone. Archaeometry, 58(3), 484-499. https://doi.org/10.1111/arcm.12190.

10. Booth, T. (2017). The rot sets in: low-powered microscopic investigation of taphonomic changes to bone microstructure and its application to funerary contexts. In D. Errickson, \& T. Thompson (Eds.), Human remains: another dimension: the application of imaging to the study of human remains (pp. 7-28). Academic Press. https://doi.org/10.1016/b978-0-12804602-9.00003-5.

11. Booth, T. J., Redfern, R. C., \& Gowland, R. L. (2016). Immaculate conceptions: micro-CT analysis of diagenesis in RomanoBritish infant skeletons. Journal of Archaeological Science, 74, 124-134. https://doi.org/10.1016/j.jas.2016.08.007.

12. Boschin, F., Zanolli, C., Bernardini, F., Princivalle, F., \& Tuniz, C. (2015). A look from the inside: microCT analysis of burned bones. Ethnobiology Letters, 6(2), 258-266. https://doi.org/10.14237/ebl.6.2.2015.365.

13. Boskey, A. L. (2013). Bone composition: relationship to bone fragility and antiosteoporotic drug effects. BoneKEy Reports, 2, 447. https://doi.org/10.1038/bonekey.2013.181.

14. Bradfield, J. (2018). Identifying animal taxa used to manufacture bone tools during the Middle Stone Age at Sibudu, South Africa: results of a CT-rendered histological analysis. PLOS ONE, 13(11), e0208319.

https://doi.org/10.1371/journal.pone.0208319.

15. Brönnimann, D., Portmann, C., Pichler, S. L., Booth, T. J., Röder, B., Vach, W. ... Rentzel, P. (2018). Contextualising the dead combining geoarchaeology and osteo-anthropology in a new multi-focus approach in bone histotaphonomy. Journal of Archaeological Science, 98, 45-58. https://doi.org/10.1016/j.jas.2018.08.005.

16. Caruso, V., Marinoni, N., Diella, V., Berna, F., Cantaluppi, M., Mancini, L. ... Pavese, A. (2020). Bone diagenesis in archaeological and contemporary human remains: an investigation of bone 3D microstructure and minero-chemical assessment. Archaeological and Anthropological Sciences, 12, 162. https://doi.org/10.1007/s12520-020-01090-6.

17. Child, A. M. (1995). Towards an understanding of the microbial decomposition of archaeological bone in the burial environment. Journal of Archaeological Science, 22(2), 165-174. https://doi.org/10.1006/jasc.1995.0018.

18. Dal Sasso, G., Maritan, L., Usai, D., Angelini, I., \& Artioli, G. (2014). Bone diagenesis at the micro-scale: bone alteration patterns during multiple burial phases at Al Khiday (Khartoum, Sudan) between the Early Holocene and the II century AD. Palaeogeography, Palaeoclimatology, Palaeoecology, 416, 30-42. https://doi.org/10.1016/j.palaeo.2014.06.034.

19. Damann, F. E., \& Jans, M. M. E. (2017). Microbes, anthropology, and bones. In Carter, D. O., Tomberlin, J. K., Benbow, M. E., \& Metcalf, J. L. (Eds.), Forensic microbiology (pp. 312-327). Wiley

20. Ellingham, S., \& Sandholzer, M. A. (2020). Determining volumetric shrinkage trends of burnt bone using micro-CT. Journal of Forensic Sciences, 65(1), 196-199. https://doi.org/10.1111/1556-4029.14150.

21. Fernández-Jalvo, Y., Andrews, P., Pesquero, D., Smith, C., Marín-Monfort, D., Sánchez, B. ... Alonso, A. (2010). Early bone diagenesis in temperate environments: Part I: surface features and histology. Palaeogeography, Palaeoclimatology, Palaeoecology, 288(1-4), 62-81. https://doi.org/10.1016/j.palaeo.2009.12.016.

22. Frost, H. M. (1961). Human Haversian system measurements. Henry Ford Hospital Medical Bulletin, 9(1), 145-147

23. Garland, A. N. (1987). A histological study of archaeological bone decomposition. In Boddington, A., Garland, A. N., \& Janaway, R. C. (Eds.), Death, decay and reconstruction: approaches to archaeology and forensic science (pp. 109-126). Manchester University Press

24. Grupe, G., \& Garland, A. N. (1993). Histology of ancient bone: methods and diagnosis. Springer

25. Grupe, G., \& Dreses-Werringloer, U. (1993). Decomposition phenomena in thin-sections of excavated human bones. In Grupe, G., \& Garland, A. N. (Eds.), Histology of ancient human bone: methods and diagnosis (pp. 27-36). Springer

26. Hackett, C. J. (1981). Microscopical focal destruction (tunnels) in exhumed human bones. Medicine, Science and the Law, 21(4), 243-265. https://doi.org/10.1177/002580248102100403. 
27. Handschuh, S., Schwaha, T., \& Metscher, B. D. (2010). Showing their true colors: a practical approach to volume rendering from serial sections. BMC Developmental Biology, 10, 41. https://doi.org/10.1186/1471-213X-10-41.

28. Handschuh, S., Beisser, C. J., Ruthensteiner, B., \& Metscher, B. D. (2017). Microscopic dual-energy CT (microDECT): a flexible tool for multichannel ex vivo 3D imaging of biological specimens. Journal of Microscopy, 267, 3-26. https://doi.org/10.1111/jmi.12543

29. Hanson, M., \& Cain, C. R. (2007). Examining histology to identify burned bone. Journal of Archaeological Science, 34(11), 1902-1913. https://doi.org/10.1016/j.jas.2007.01.009.

30. Hedges, R. E. M., Millard, A. R., \& Pike, A. W. G. (1995). Measurements and relationships of diagenetic alteration of bone from three archaeological sites. Journal of Archaeological Science, 22(2), 201-209.

https://doi.org/10.1006/jasc.1995.0022.

31. Higgs, N. D., Glover, A. G., Dahlgren, T. G., \& Little, C. T. S. (2011). Bone-boring worms: characterizing the morphology, rate, and method of bioerosion by Osedax mucofloris (Annelida, Siboglinidae). The Biological Bulletin, 221(3), 307-316. https://doi.org/10.1086/BBLv221n3p307.

32. Hollund, H. I., Jans, M. M. E., Collins, M. J., Kars, H., Joosten, I., \& Kars, S. M. (2012). What happened here? Bone histology as a tool in decoding the postmortem histories of archaeological bone from Castricum, The Netherlands. International Journal of Osteoarchaeology, 22(5), 537-548. https://doi.org/10.1002/oa.1273.

33. Hollund, H. I., Blank, M., \& Sjögren, K. G. (2018). Dead and buried? Variation in post-mortem histories revealed through histotaphonomic characterisation of human bone from megalithic graves in Sweden. PLoS ONE, 13(10), e0204662. https://doi.org/10.1371/journal.pone.0204662.

34. Hunger, H., \& Leopold, D. (1978). Identifikation. Springer

35. Jackes, M., Sherburne, R., Lubell, D., Barker, C., \& Wayman, M. (2001). Destruction of microstructure in archaeological bone: a case study from Portugal. International Journal of Osteoarchaeology, 11(6), 415-432. https://doi.org/10.1002/oa.583.

36. Janaway, R. C. (1996). The decay of buried human remains and their associated material. In Hunter, J., Roberts, C., \& Martin, A. (Eds.), Studies in crime: an introduction to forensic Archaeology (pp. 58-85). B. T. Batsford Ltd

37. Jans, M. M. E. (2008). Microbial bioerosion of bone - a review. In Wisshak, M., \& Tapanila, L. (Eds.), Current developments in bioerosion (pp. 397-413). Springer

38. Jans, M. M. E., Kars, H., Nielsen-Marsh, C. M., Smith, C. I., Nord, A. G., Arthur, P., \& Earl, N. (2002). In situ preservation of archaeological bone: a histological study within a multidisciplinary approach. Archaeometry, 44(3), 343-352. https://doi.org/10.1111/1475-4754.t01-1-00067.

39. Jans, M. M. E., Nielsen-Marsh, C. M., Smith, C. I., Collins, M. J., \& Kars, H. (2004). The characterisation of microbial attack in archaeological bone. Journal of Archaeological Science, 31(1), 87-95. https://doi.org/10.1016/j.jas.2003.07.007.

40. Kendall, C., Høier Eriksen, A. M., Kontopoulos, I., Collins, M. J., \& Turner-Walker, G. (2018). Diagenesis of archaeological bone and tooth. Palaeogeography, Palaeoclimatology, Palaeoecology, 491, 21-37. https://doi.org/10.1016/j.palaeo.2017.11.041.

41. Kontopoulos, I., Nystrom, P., \& White, L. (2016). Experimental taphonomy: post-mortem microstructural modifications in Sus scrofa domesticus bone. Forensic Science International, 266, 320-328.

https://doi.org/10.1016/j.forsciint.2016.06.024.

42. Le Garff, E., Mesli, V., Delannoy, Y., Colard, T., Demondion, X., Becart, A., \& Hedouin, V. (2017). Technical note: early postmortem changes of human bone in taphonomy with $\mu \mathrm{CT}$. International Journal of Legal Medicine, 131, 761-770. https://doi.org/10.1007/s00414-016-1509-y.

43. Lemmers, S. A. M., Gonçalves, D., Cunha, E., Vassalo, A. R., \& Appleby, J. (2020). Burned flesh or dry? The potential of bioerosion to determine the pre-burning condition of human remains. Journal of Archaeological Method and Theory, 27, 972-991. https://doi.org/10.1007/s10816-020-09446-x.

44. Marchiafava, V., Bonucci, E., \& Ascenzi, A. (1974). Fungal osteoclasia: a model of dead bone resorption. Calcified Tissue Research, 14, 195-210. https://doi.org/10.1007/BF02060295.

Page 23/38 
45. Metcalf, J. L., Xu, Z., Weiss, Z., Lax, S., Van Treuren, S., Hyde, W. ... Knight, R., D. O., \&. (2016). Microbial community assembly and metabolic function during mammalian corpse decomposition. Science, 351(6269), 158-162. https://doi.org/10.1126/science.aad2646.

46. Millard, A. M. (2001). The deterioration of bone. In Pollard, A. M., \& Brothwell, D. R. (Eds.), Handbook of archaeological science (pp. 633-643). Wiley

47. Moore, M. K. (2013). Functional morphology and medical imaging. In E. A. DiGangi, \& M. K. Moore (Eds.), Research methods in human skeletal biology (pp. 397-424). Academic Press. https://doi.org/10.1016/B978-0-12-385189-5.00014-5.

48. Müller, R., Van Campenhout, H., Van Damme, B., Van Der Perre, G., Dequeker, J., Hildebrand, T., \& Rüegsegger, P. (1998). Morphometric analysis of human bone biopsies: a quantitative structural comparison of histological sections and microcomputed tomography. Bone, 23(1), 59-66. https://doi.org/10.1016/s8756-3282(98)00068-4.

49. Nielsen-Marsh, C. M., Smith, C. I., Jans, M. M. E., Nord, A., Kars, H., \& Collins, M. J. (2007). Bone diagenesis in the European Holocene II: taphonomic and environmental considerations. Journal of Archaeological Science, 34(9), 1523-1531. https://doi.org/10.1016/J.JAS.2006.11.012.

50. Particelli, F., Mecozzi, L., Beraudi, A., Montesi, M., Baruffaldi, F., \& Viceconti, M. (2012). A comparison between micro-CT and histology for the evaluation of cortical bone: effect of polymethylmethacrylate embedding on structural parameters. Journal of Microscopy, 245(3), 302-310. https://doi.org/10.1111/j.1365-2818.2011.03573.x.

51. Piepenbrink, H. (1986). Two examples of biogenous dead bone decomposition and their consequences for taphonomic interpretation. Journal of Archaeological Science, 13(5), 417-430. https://doi.org/10.1016/0305-4403(86)90012-9.

52. Rühli, F. J., Kuhn, G., Evison, R., Müller, R., \& Schultz, M. (2007). Diagnostic value of micro-CT in comparison with histology in the qualitative assessment of historical human skull bone pathologies. American Journal of Physical Anthropology, 133(4), 1099-1111. https://doi.org/10.1002/ajpa.20611.

53. Ryan, T. M., \& Sukhdeo, S. (2016). KSD-VP-1/1: analysis of the postcranial skeleton using high-resolution computed tomography. In Haile-Selassie, Y., \& Su, D. F. (Eds.), The postcranial anatomy of Australopithecus afarensis: new insights from KSD-VP-1/1 (pp. 39-62). Springer

54. Safadi, F. F., Barbe, M. F., Abdelmagid, S. M., Rico, M. C., Aswad, R. A., Litvin, J., \& Popoff, S. N. (2009). Bone structure, development and bone biology. In Khurana, J. S. (Ed.), Bone Pathology (2nd ed., pp. 1-50). Humana Press

55. Scherf, H. (2013). Computed tomography in paleoanthropology - an overview. Archaeological and Anthropological Science, 5, 205-214. https://doi.org/10.1007/s12520-013-0128-5.

56. Schindelin, J., Arganda-Carreras, I., Frise, E., Kaynig, V., Longair, M., Pietzsch, T. ... Cardona, A. (2012). Fiji: an open-source platform for biological-image analysis. Nature Methods, 9, 676-682. https://doi.org/10.1038/nmeth.2019

57. Schroeder, W., Martin, K., \& Lorensen, B. (2018). The visualization toolkit: an object-oriented approach to 3D graphics: edition 4.1. Retrieved April 20, 2021, from

https://raw.githubusercontent.com/lorensen/VTKExamples/master/src/VTKBookLaTeX/VTKTextBook.pdf.

58. Schultz, M. (1986). Die mikroskopische Untersuchung prähistorischer Skeletfunde: Anwendung und Aussagemöglichkeiten der differentialdiagnostischen Untersuchung (Archäologie und Museum Vol. 1,6). Retrieved October 8, 2021, from https://www.archaeologie.bl.ch/uploads/files/website/Die_mikroskopische_Untersuchung_prahistorische_Skeletfunde.pdf.

59. Schultz, M. (2001). Paleohistopathology of bone: a new approach to the study of ancient diseases. Yearbook of Physical Anthropology, 44, 106-147. https://doi.org/10.1002/ajpa.10024.

60. Seeman, E. (2013). Age- and menopause-related bone loss compromise cortical and trabecular microstructure. Journal of Gerontology: Series A, 68(10), 1218-1225. https://doi.org/10.1093/gerona/glt071.

61. Smith, C. I., Nielsen-Marsh, C. M., Jans, M. M. E., Arthur, P., Nord, A. G., \& Collins, M. J. (2002). The strange case of Apigliano: early 'fossilization' of medieval bone in southern Italy. Archaeometry, 44(3), 405-415. https://doi.org/10.1111/1475-4754.T01-1-00073.

62. Thermo Scientific ${ }^{T M}$ Thermo ScientificTM AmiraTM Software 6: User's Guide. Retrieved October 13, 2020, from https://assets.thermofisher.com/TFS-Assets/MSD/Product-Guides/user-guide-amira-software.pdf. 
63. Turner-Walker, G., \& Syversen, U. (2002). Quantifying histological changes in archaeological bones using BSE-SEM image analysis. Archaeometry, 44(3), 461-468. https://doi.org/10.1111/1475-4754.t01-1-00078.

64. Turner-Walker, G., Nielsen-Marsh, C. M., Syversen, U., Kars, H., \& Collins, M. J. (2002). Sub-micron spongiform porosity is the major ultra-structural alteration occurring in archaeological bone. International Journal of Osteoarchaeology, 12(6), 407414. https://doi.org/10.1002/oa.642.

65. Turner-Walker, G., \& Jans, M. (2008). Reconstructing taphonomic histories using histological analysis. Palaeogeography, Palaeoclimatology, Palaeoecology, 266(3-4), 227-235. https://doi.org/10.1016/j.palaeo.2008.03.024.

66. Turner-Walker, G., \& Peacock, E. E. (2008). Preliminary results of bone diagenesis in Scandinavian bogs. Palaeogeography, Palaeoclimatology, Palaeoecology, 266(3-4), 151-159. https://doi.org/10.1016/j.palaeo.2008.03.027.

67. Turner-Walker, G. (2012). Early bioerosion in skeletal tissues: persistence through deep time. Neues Jahrbuch für Geologie und Paläontologie, 265(2), 165-183. https://doi.org/10.1127/0077-7749/2012/0253.

68. Turner-Walker, G. (2019). Light at the end of the tunnels? The origins of microbial bioerosion in mineralised collagen. Palaeogeography, Palaeoclimatology, Palaeoecology, 529, 24-38. https://doi.org/10.1016/j.palaeo.2019.05.020.

69. Uchiyama, T., Tanizawa, T., Muramatsu, H., Endo, N., Takahashi, H. E., \& Hara, T. (1997). A morphometric comparison of trabecular structure of human ilium between microcomputed tomography and conventional histomorphometry. Calcified Tissue International, 61, 493-498. https://doi.org/10.1007/s002239900373.

70. Walton, L. A., Bradley, R. S., Withers, P. J., Newton, V. L., Watson, R. E. B., Austin, C., \& Sherratt, M. J. (2015). Morphological characterisation of unstained and intact tissue micro-architecture by X-ray computed micro- and nano-tomography. Scientific Reports, 5, 10074. https://doi.org/10.1038/srep10074.

71. Wedl, C. (1865). Über einen im Zahnbein und Knochen keimenden Pilz. Sitzungsberichte der mathematischnaturwissenschaftlichen Classe der Kaiserlichen Akademie der Wissenschaften, 50(1864), 171-193

72. White, L., \& Booth, T. J. (2014). The origin of bacteria responsible for bioerosion to the internal bone microstructure: results from experimentally-deposited pig carcasses. Forensic Science International, 239, 92-102.

https://doi.org/10.1016/j.forsciint.2014.03.024.

73. White, T. D., Black, M. T., \& Folkens, P. A. (2012). Human osteology (3rd edition). Academic Press.

74. Withers, P. J., Bouman, C., Carmignato, S., Cnudde, V., Grimaldi, D., Hagen, C. K. ... Stock, S. R. (2021). X-ray computed tomography. Nature Reviews Methods Primers, 1, 18. https://doi.org/10.1038/s43586-021-00015-4

75. Yoshino, M., Kimijima, T., Miyasaka, S., Sato, H., \& Seta, S. (1991). Microscopical study on estimation of time since death in skeletal remains. Forensic Science International, 49, 143-158. https://doi.org/10.1016/0379-0738(91)90074-s.

\section{Figures}



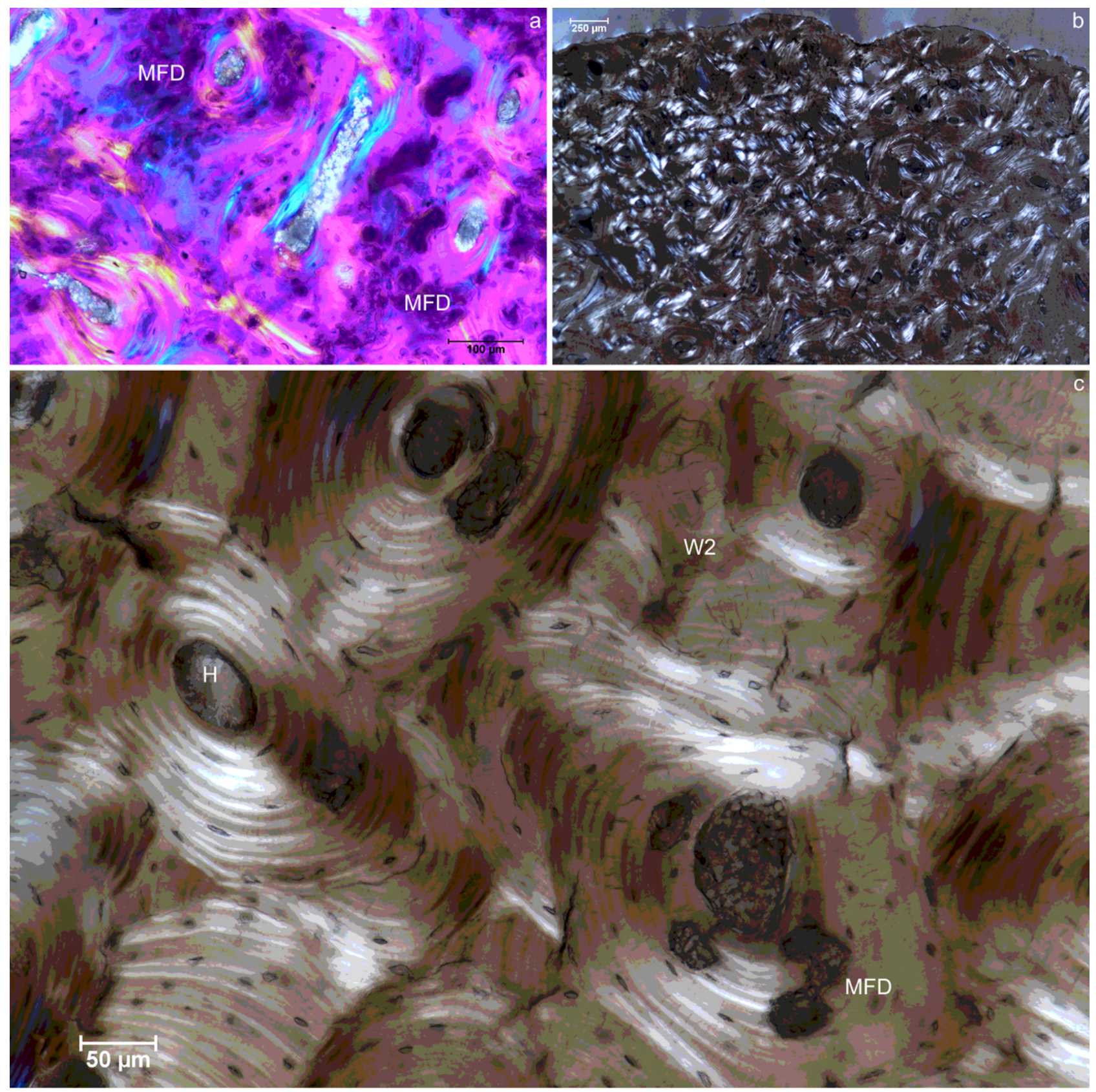

\section{Figure 1}

Light micrographs showing the described histological features. (a) Inhibited bioerosion (MFD) and recrystallization in canals in femoral sample S01. The blue and yellow visualize collagen birefringence. The micrograph was taken with a lambda plate and 10(2x) magnification. (b) Very good collagen preservation and inhibited bioerosion in femoral sample GÖ01. The micrograph was taken with polarized light and $4(1 \times)$ magnification. (c) Inhibited bioerosion around Haversian canals $(\mathrm{H})$ with Wedl type-2 tunnelling (W2) identified by enlarged canaliculi in femoral sample GÖ01. The micrograph was taken with polarized light and 10(2x) magnification 

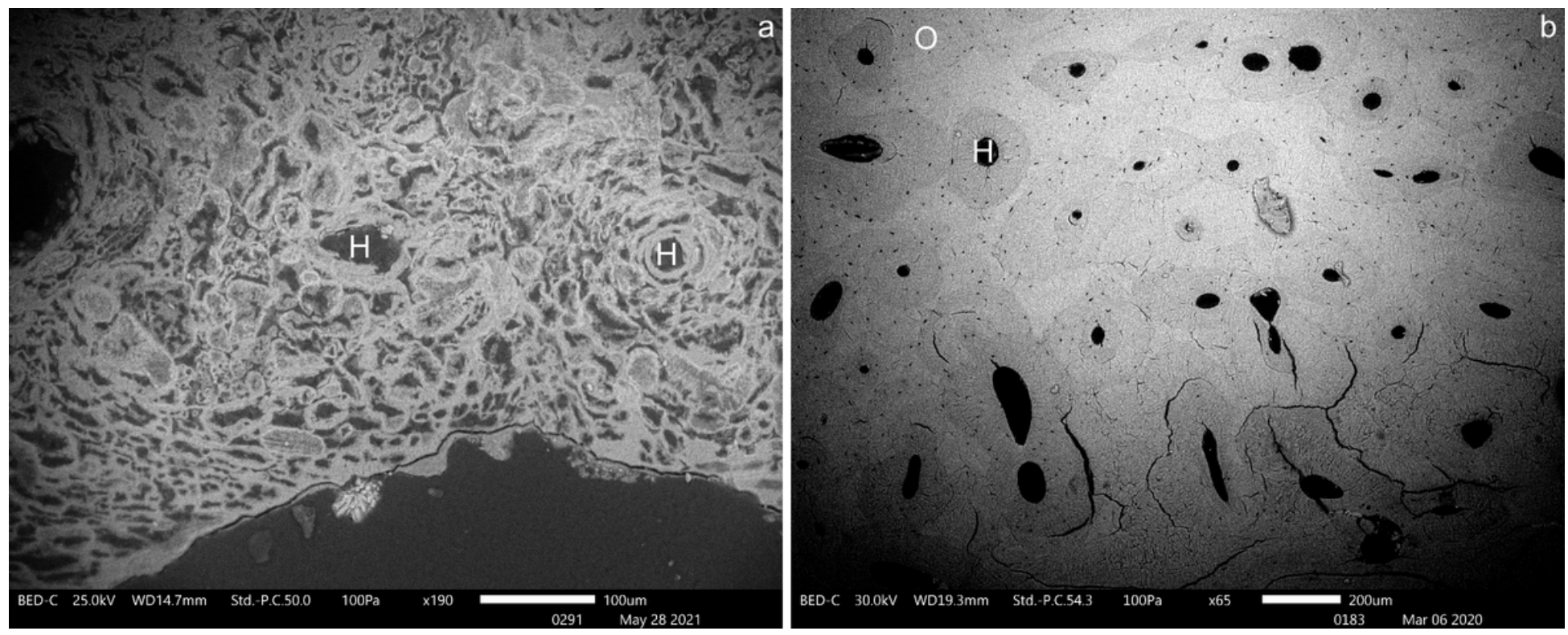

\section{Figure 2}

SEM-BSE images of two femora. (a) Complete destruction of microanatomy (OHI 0) by bioerosion with only Haversian canals $(\mathrm{H})$ remaining in sample S02. (b) Perfectly preserved microanatomy $(\mathrm{OHI} 5)$ with clearly identifiable osteocytes $(0)$ in sample GÖ04 


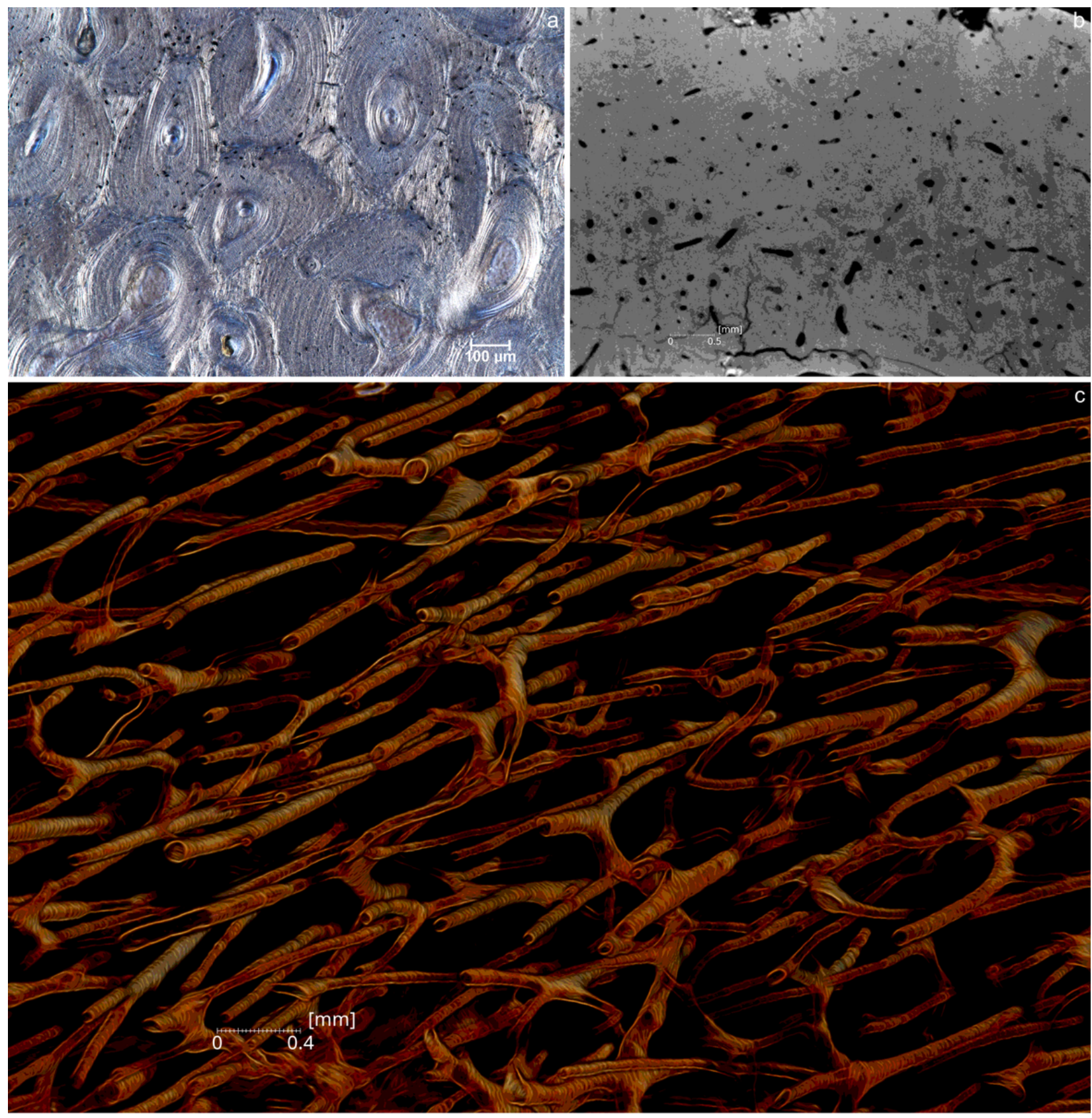

\section{Figure 3}

Sample GÖ04, a late juvenile female. (a) Light micrograph of midline of a transverse histological thin section (interference phase contrast under 10(1x) magnification). (b) Single virtual transverse cross-section (1 voxel [6.7 $\mu \mathrm{m}]$ thick) through a microCT image showing midline and periosteal surface. (c) 3D volume rendering of entire virtual dataset showing midline 

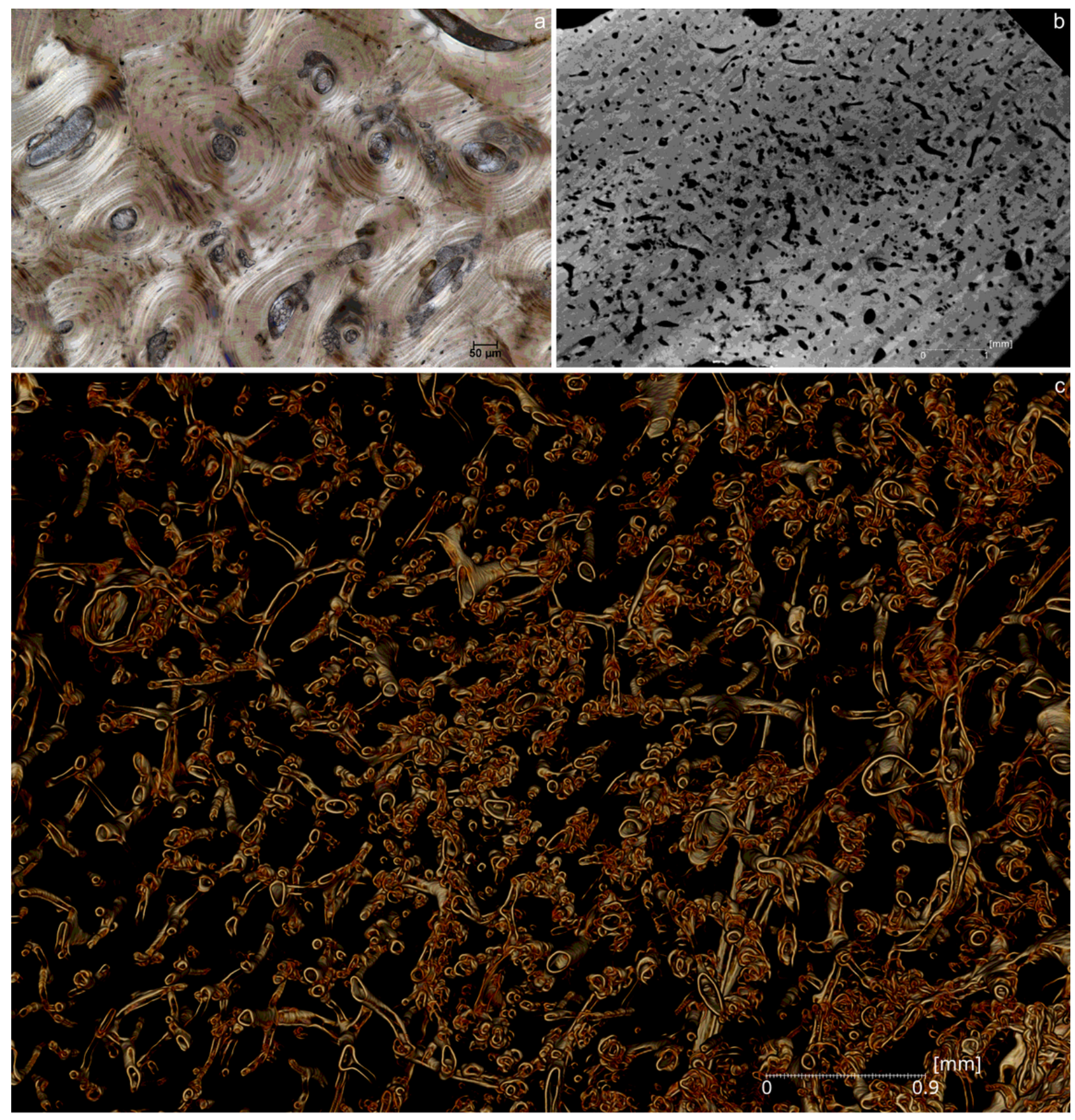

\section{Figure 4}

Sample GÖ01, an early adult female. (a) Light micrograph of midline of a transverse histological thin section (polarized light and under 10(2x) magnification). (b) Single virtual transverse cross-section (1 voxel [8.0 $\mu \mathrm{m}]$ thick) through a microCT image showing midline, and periosteal and endosteal surfaces. (c) 3D volume rendering of entire virtual dataset showing midline 


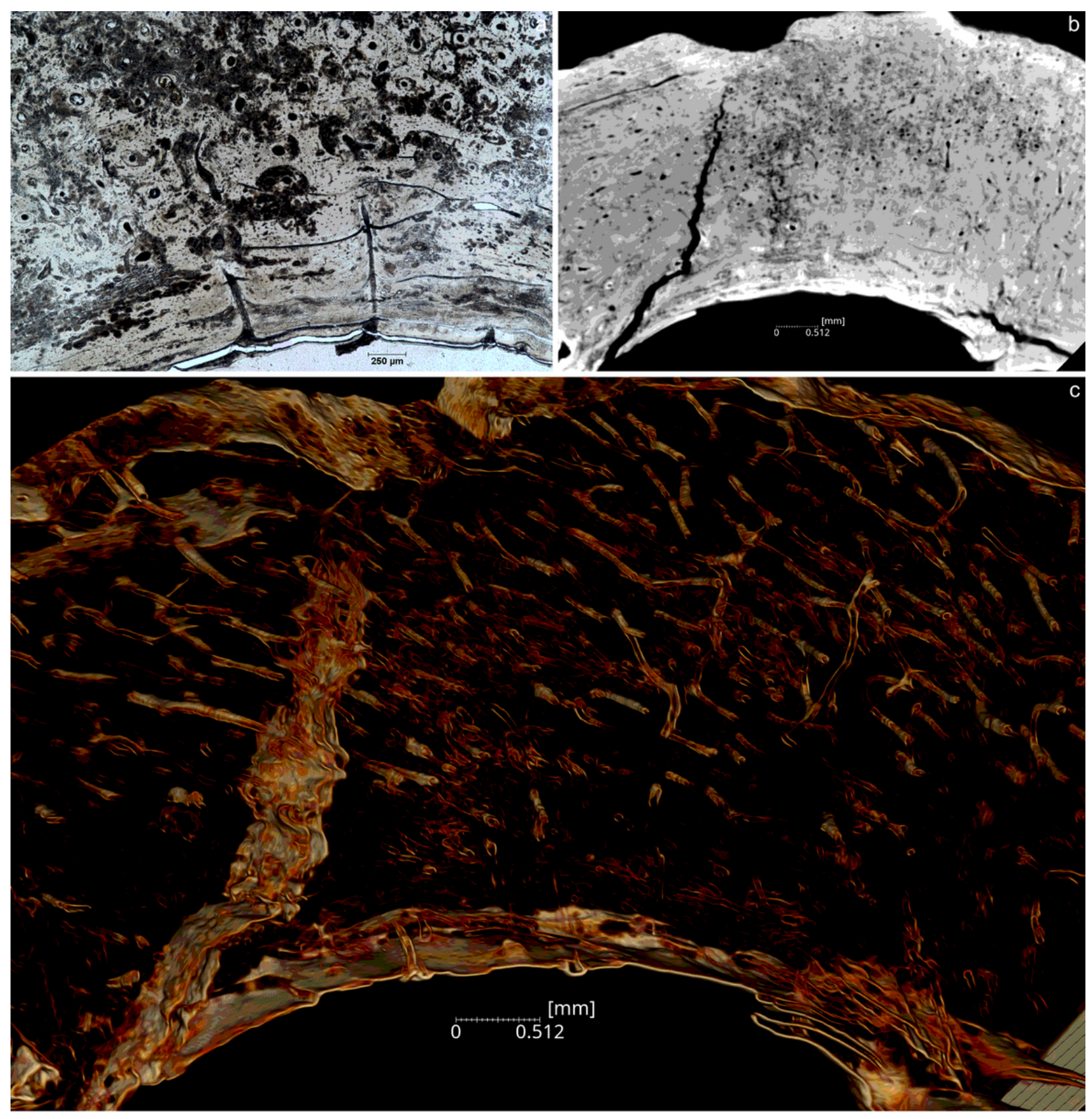

\section{Figure 5}

Sample S01, an early adult female. (a) Light micrograph of midline and endosteum of a transverse histological thin section (plane light under $4(1 \times)$ magnification). b) Single virtual transverse cross-section (1 voxel [8.0 $\mu \mathrm{m}]$ thick) through a microCT image showing midline, and periosteal and endosteal surfaces. c) 3D volume rendering of entire virtual dataset showing midline, and periosteal and endosteal surfaces 

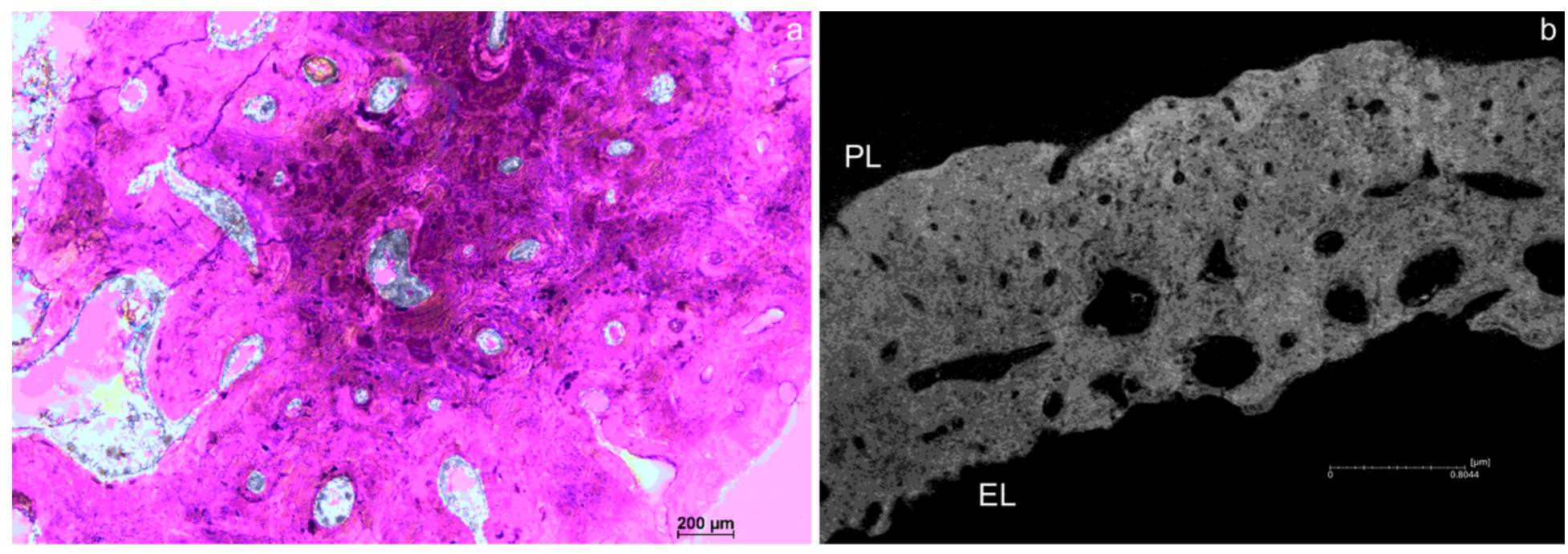

\section{Figure 6}

Sample S04, a late mature female. (a) Micrograph of midline and endosteum of a transverse histological thin section (lambda plate and 4(1.25x) magnification). (b) Single virtual transverse microCT cross-section ( 1 voxel [4.0 $\mu \mathrm{m}]$ thick) showing midline, and periosteal and endosteal surfaces 


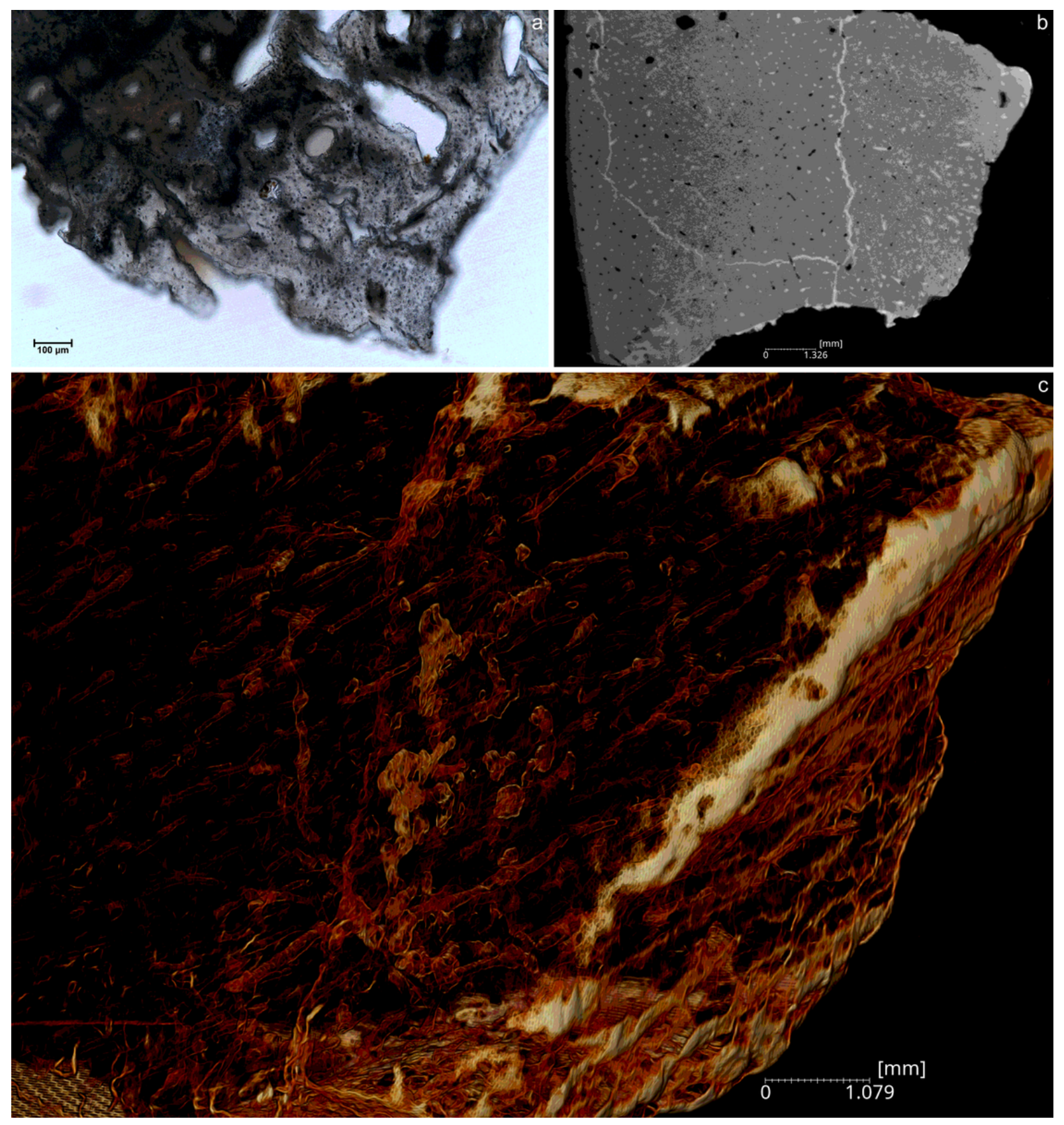

\section{Figure 7}

Sample IN01, an adult-mature female. (a) Light micrograph of midline and endosteum of a transverse histological thin section (plane-polarized light and 10(1x) magnification). (b) Single virtual transverse microCT cross-section (1 voxel [10.9 $\mu \mathrm{m}]$ thick) showing midline, and periosteal and endosteal surfaces. (c) 3D volume rendering of entire virtual dataset showing midline and periosteum 
10

8 등 6

4
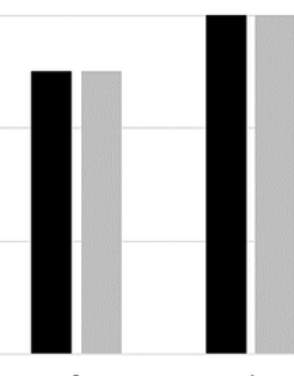

0
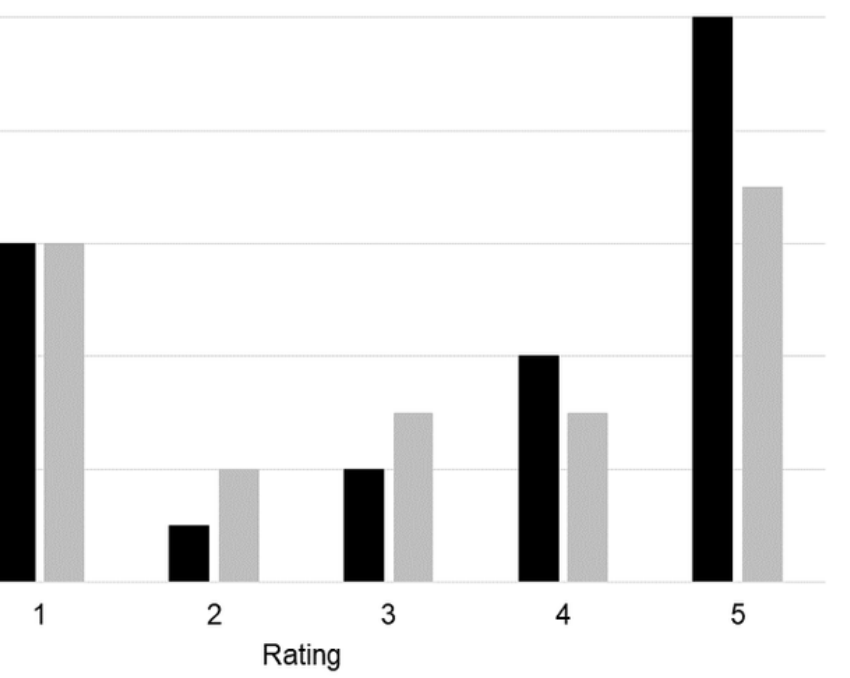

- Observer 1

- Observer 2

12

b

10

8

동 6

4

4

2
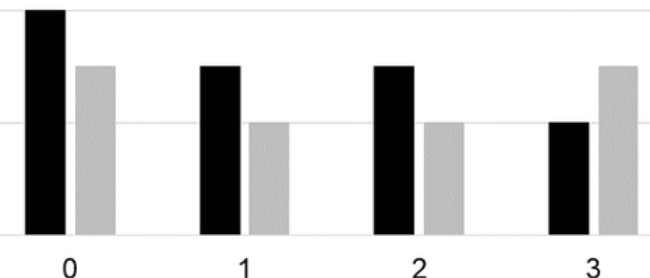

2

3

Rating

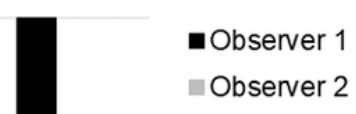

Figure 8

Frequency of a) $\mathrm{OHI}$ ratings per observer. b) $\mathrm{VHI}$ ratings per observer 


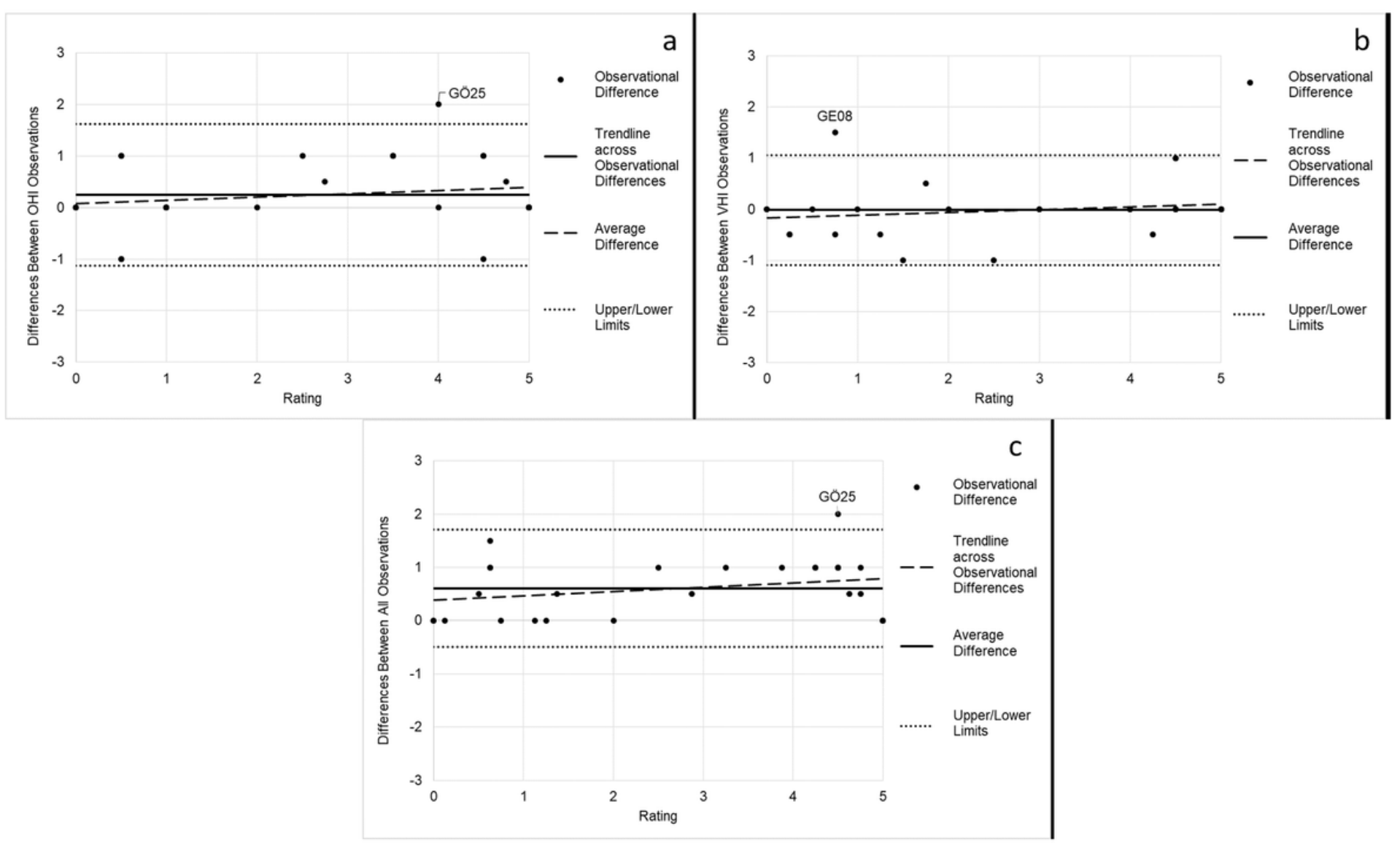

Figure 9

Bland-Altman plot (a) Differences between OHI observations. (b) Differences between VHI observations. (c) Differences between all observations 


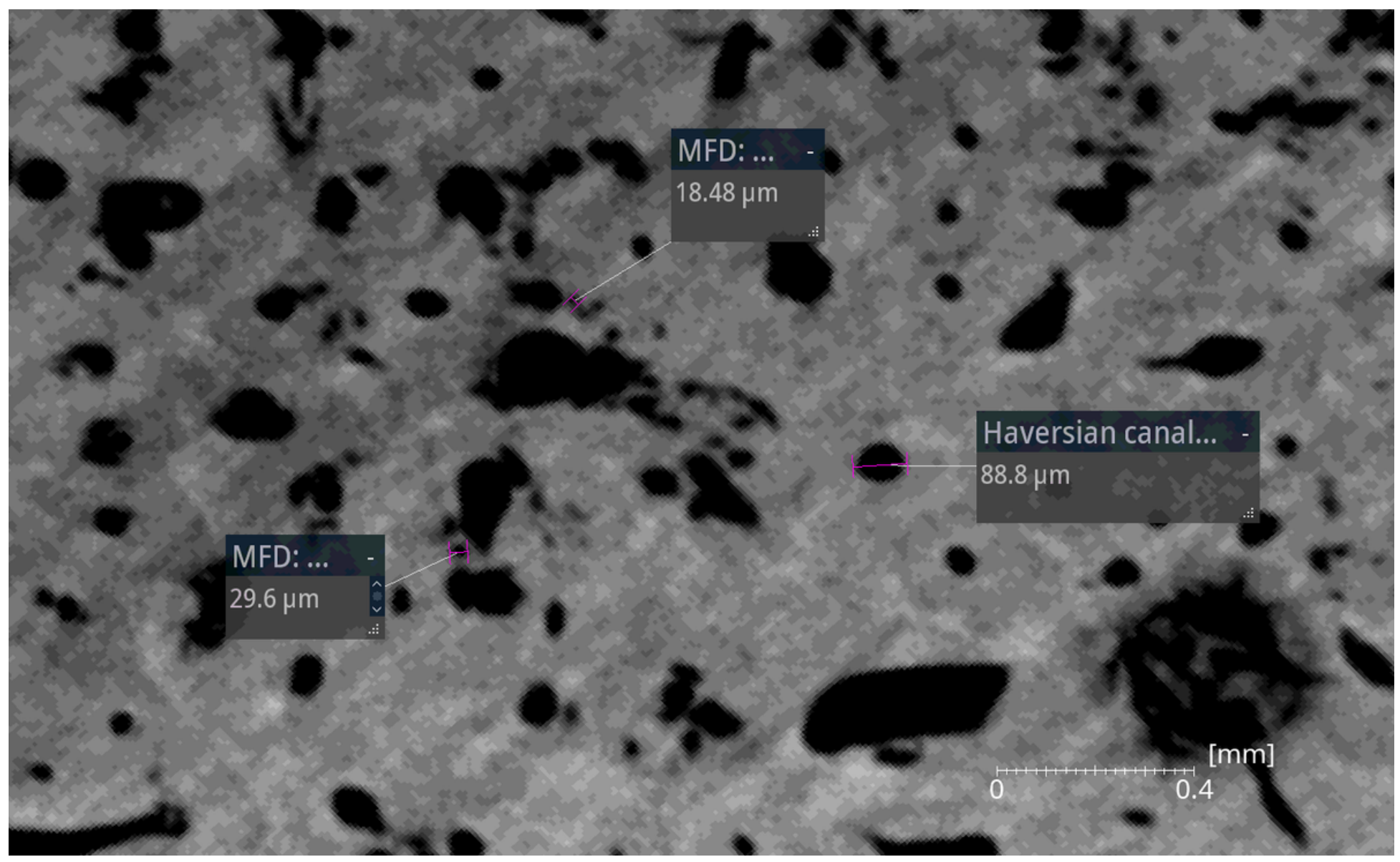

\section{Figure 10}

Virtual measurements of MFD and Haversian canal in midline of a single virtual transverse cross-section (1 voxel [8.0 $\mu \mathrm{m}]$ thick) of femoral sample GÖ01 


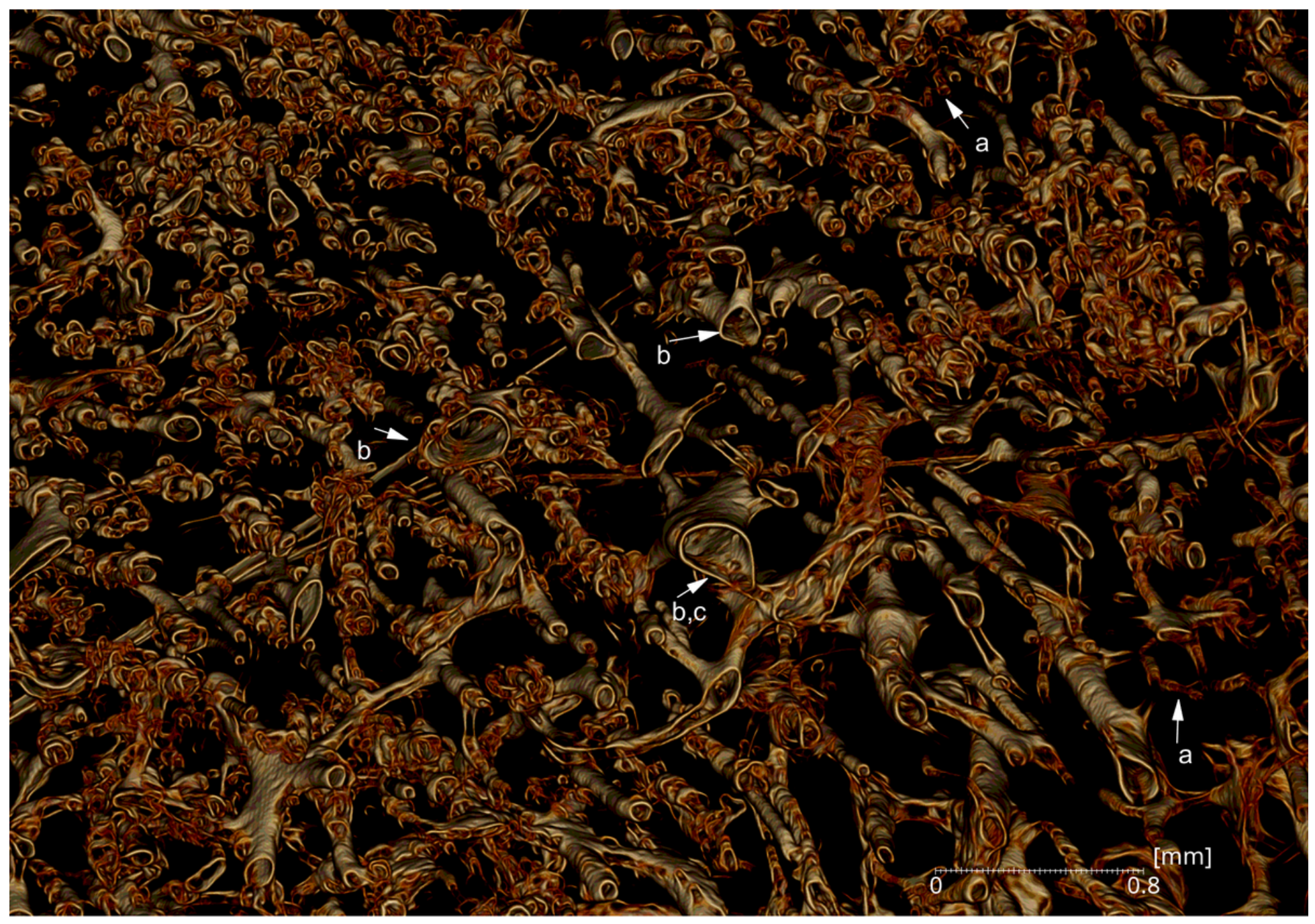

Figure 11

3D volume rendering showing MFD tunneling (a), red trails of bioerosion (b) and miniscule holes in Haversian canals (c) in midline of femoral sample GÖ01 


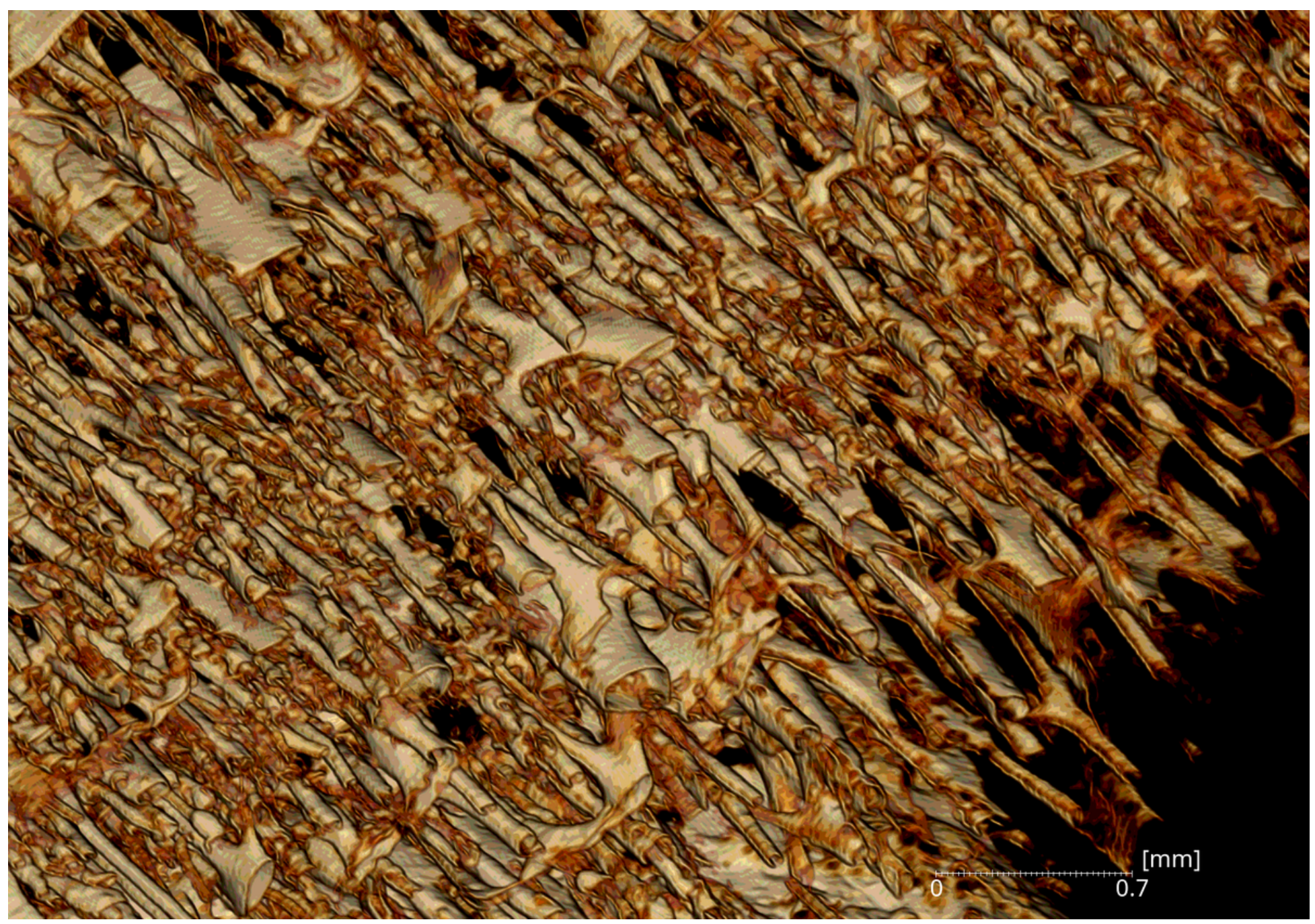

Figure 12

3D volume rendering showing MFD tunneling in femoral sample GÖ01

\section{Supplementary Files}

This is a list of supplementary files associated with this preprint. Click to download.

- ESM1.xIsx

- ESM10.tif

- ESM11.tif

- ESM12.tif

- ESM13.tif

- ESM14.tif

- ESM15.tif

- ESM16.tif

- ESM17.tif

- ESM18.tif

- ESM19.tif

- ESM2.xlsx 
- ESM20.tif

- ESM21.tif

- ESM22.tif

- ESM23.tif

- ESM24.tif

- ESM25.tif

- ESM26.tif

- ESM27.tif

- ESM3.xIsx

- ESM4.tif

- ESM5.tif

- ESM6.tif

- ESM7.tif

- ESM8.tif

- ESM9.tif 